NBER WORKING PAPER SERIES

WHEN CHILDREN RULE:

PARENTING IN MODERN FAMILIES

\author{
Sebastian Galiani \\ Matthew Staiger \\ Gustavo Torrens \\ Working Paper 23087 \\ http://www.nber.org/papers/w23087
}

\author{
NATIONAL BUREAU OF ECONOMIC RESEARCH \\ 1050 Massachusetts Avenue \\ Cambridge, MA 02138 \\ January 2017
}

The views expressed herein are those of the authors and do not necessarily reflect the views of the National Bureau of Economic Research.

NBER working papers are circulated for discussion and comment purposes. They have not been peer-reviewed or been subject to the review by the NBER Board of Directors that accompanies official NBER publications.

(C) 2017 by Sebastian Galiani, Matthew Staiger, and Gustavo Torrens. All rights reserved. Short sections of text, not to exceed two paragraphs, may be quoted without explicit permission provided that full credit, including $\odot$ notice, is given to the source. 
When Children Rule: Parenting in Modern Families

Sebastian Galiani, Matthew Staiger, and Gustavo Torrens

NBER Working Paper No. 23087

January 2017

JEL No. J13

\begin{abstract}
$\underline{\text { ABSTRACT }}$
During the 20th century there was a secular transformation within American families from a household dominated by the father to a more egalitarian one in which the wife and the children have been empowered. This transformation coincided with two major economic and demographic changes, namely the increase in economic opportunities for women and a decline in family size. To explain the connection between these trends and the transformation in family relationships we develop a novel model of parenting styles that highlights the importance of competition within the family. The key intuition is that the rise in relative earnings of wives increased competition between spouses for the love and a ection of their children while the decline in family size reduced competition between children for resources from their parents. The combined e ect has empowered children within the household and allowed them to capture an increasing share of the household surplus over the past hundred years.

Sebastian Galiani

Department of Economics

University of Maryland

3105 Tydings Hall

College Park, MD 20742

and NBER

galiani@econ.umd.edu

Matthew Staiger

Tydings Hall

Universidy of Maryland

College Park

staiger@econ.umd.edu

Gustavo Torrens

Department of Economics

Indiana University

Wylie Hall, 100 S Woodland Ave

Bloomington, IN 47405-7104

gtorrens@indiana.edu
\end{abstract}




\title{
When Children Rule: Parenting in Modern Families
}

\author{
Sebastian Galiani* \\ University of Maryland and NBER
}

\author{
Matthew Staiger ${ }^{\dagger}$ \\ University of Maryland
}

Gustavo Torrens ${ }^{\ddagger}$

Indiana University

January 2017

\begin{abstract}
During the $20^{\text {th }}$ century there was a secular transformation within American families from a household dominated by the father to a more egalitarian one in which the wife and the children have been empowered. This transformation coincided with two major economic and demographic changes, namely the increase in economic opportunities for women and a decline in family size. To explain the connection between these trends and the transformation in family relationships we develop a novel model of parenting styles that highlights the importance of competition within the family. The key intuition is that the rise in relative earnings of wives increased competition between spouses for the love and affection of their children while the decline in family size reduced competition between children for resources from their parents. The combined effect has empowered children within the household and allowed them to capture an increasing share of the household surplus over the past hundred years.
\end{abstract}

JEL Classification: D13, J13

Keywords: family economics, parenting styles, competition

\section{Introduction}

Over the course of the $20^{t h}$ century there has been a secular shift in the nature of relationships within American families. In the early 1900's the typical father was the dominant head of the household and commanded the respect of his wife and children. The family has since become a more egalitarian

\footnotetext{
*E-mail: galiani@econ.umd.edu

${ }^{\dagger}$ E-mail: staiger@econ.umd.edu

${ }^{\ddagger}$ E-mail: gtorrens@indiana.edu
} 
organization. We argue that this shift in the distribution of power within the household is intimately connected to economic and demographic changes that occurred during the same period. More specifically, the decline in family size and the improvement in the economic opportunities for women have empowered children within the household and transformed parenting styles. We document trends in the earning gap between husbands and wives, family size and parenting styles and explain the connection between the three using a novel model of parenting that highlights the role of competition within the family. In particular, we conceptualize the family as an environment in which individuals compete with each other over scarce resources (material and emotional). A decline in family size reduces competition between siblings for resources from their parents while an increase in female earnings leads to greater competition between parents for the love and affection of their children. The combined effect improves the bargaining position of children and explains why we moved towards a family in which the children rule.

We develop a noncooperative model of the family in which parenting styles emerge as a Nash equilibrium. The utility of the children is determined by their own behavior and the material investment they receive from their parents, for which they compete with their siblings. We model this competitive process as an auction in which children offer good behavior (behavior preferred by the parents but not by the children) in return for material investment from the parents. The children are willing to be well behaved when the investment they can potentially receive is large. Parents care about the behavior of their children and their own material consumption. Both parents have the ability to influence the children through material investment using their own auction and we allow child behavior to be part public and part private good. This captures the idea that some types of children behavior such as effort in school are public goods -i.e., a good enjoyed by both parents- while other behaviors such as love and affection toward a parent are private goods. Likewise, we also allow for material consumption to be partially a private and public good. Each parent decides how to allocate their own earnings between material consumption and investment in the children. In equilibrium, the allocation of resources within the household is fully determined, i.e., parental investments are allocated among siblings, the behavior of the children is defined toward each parent, material consumption and investments are determined for each parent.

We use the model to explain the relationship between three empirical trends: a decline in the earnings gap between husbands and wives, a decline in the number of children per family and an increase in 
the share of the household surplus captured by the children. We show that the payoff of each child is decreasing in the number of siblings and increasing in the investments made by the parents. Moreover, we show that parental investment is independent of family size and deduce conditions under which parental investments increase as the gap between male and female earnings close. Taken together, this implies that a decline in the earnings gap and family size should increase the share of the household surplus captured by the children. Two mechanisms are behind these results. First, as there are fewer children in the household, competition for parental investments is less intense, which decreases the bids offered by each child. Second, when the behavior of the children is relatively more of a private good (relative to the degree to which material consumption is a private good), the spouse with lower earnings prefers to free-ride off the material consumption of the higher earning spouse and instead focuses all of his or her resources on influencing the behavior of the children. A reduction in the income gap between the spouses increases total parental investment because the lower earning spouse is now able to pour more resources into the fight to control the behavior of the children.

In the baseline model the only way in which parents can influence the children is through parental investment. In reality, parents also use punishment in order to impose their will and discipline the children. In an extension of the baseline model we formally introduce punishment and use the model to explain the decline in corporal punishment in the $20^{\text {th }}$ century. In our model punishment shapes the behavior of the child but causes disutility for both the parent and the child. In addition to preserving the key findings above, the equilibrium produces several interesting comparative statics related to the use of punishment. First, as total household income increases, punishment declines because parents now have more material resources to influence the behavior of their children and do not have to resort to coercion. Second, a reduction in the gap between spousal earnings leads to a more intense use of punishment. Third, a decrease in the number of children induces a less intense use of punishment if the elasticity of the expected behavior of the children in the auctions with respect to the number of children is relatively low. Thus, according to the model, empirical trends in total household income and family size should reduce the incidence of corporal punishment while the decline in the earnings gap should have increased the use of corporal punishment. Given that corporal punishment did indeed decline during the period, we posit that the former two effects dominated the latter.

This paper relates to the extensive literature on parental investments in children. The seminal work 
of Becker and Tomes (1979 and 1986) explore the role of the family in economic mobility. One strand of subsequent literature studies the nature of skill formation and has looked at: existence of critical investment periods, role of parental skills, multidimensional nature of skills, imperfect information of the skill formation process and dynamic complementaries in skill production (see Heckman and Cunha 2008, Cunha et al. 2010, Cunha et al. 2013 and Todd and Wolpin 2003, 2007). Other papers have documented the importance of parental time inputs (Del Boca 2014) and the role of the marriage market (Gayle et al. 2014). The consensus in the literature is that characteristics formed during childhood play a major role in predicting future earnings (Keane and Wolpin 1997 and Huggett et al. 2011), individuals are more malleable at younger ages (Cunha et al. 2006), and parental inputs have significant long-term impacts through skill formation. See Heckman and Mosso (2014) and Francesconi and Heckman (2016) for comprehensive reviews of this literature. Our paper seeks to contribute to this literature by explaining changes in parental investments and parenting styles with an economic model in which parenting styles are shaped by competitive forces within the household.

Much of the previously mentioned literature on parental investments focuses on the decisions of parents and treats children as passive agents. Closer to this paper are the works that treat parenting as the outcome of a two-way strategic relationship between child and parents. Becker's (1974) rotten kid theorem is an early example of a model in which children are active agents and parents influence their behavior through transfers. Several more recent papers develop richer models of parent-child interactions in an attempt to understand more nuanced aspects of parenting styles. Lizzeri and Siniscalchi (2008) present a model in which children struggle with performing tasks. Parents decide whether or not to assist their children and shield them from failure or let them work on their own and risk failure but encourage learning. Burton et al. (2002), Cosconati (2013) and Akabayashi (2006) develop models in which children have greater discount rates and thus their optimal investment in accumulating human capital is lower than what their parents would choose. In response, the parents use carrots and sticks to incentivize their children. In a recent paper, Doepke and Zilibotti (2014) argue that parenting styles are influenced by economic inequality and the returns to incumbency (working in the same profession as your parent). In their model parents are motivated by both altruism and paternalism and they influence the behavior of their children by shaping their preferences or restricting their choice sets. Our work is closely related to this recent literature in that we explicitly model both parents and children and allow parenting styles to 
arise out of a strategic interaction between children and their parents.

Our paper, however, differs from the existing literature by focusing on the role of competition within the household. Most models only consider families with one child. Of the models that do consider multiple children, siblings typically effect one another only through the resource constraint. There are a few notable exceptions that have explored parental responses to multiple children with different abilities. Behrman et al. (1982) studies how, depending on the preferences of the parent, parenting styles could amplify or mitigate innate differences across siblings. Hao et al. (2008) argue that parents tend to be stricter on older children in order to deter the younger siblings from misbehaving. Vogl (2013) illustrates how the institution of arranged marriage induces families to marry off their elder daughters at a younger age. While all of these papers explore interesting interactions between siblings, they do not explicitly model competition between family members. Rather, these models consider how parents would react optimally given multiple and heterogeneous children in the family. A key contribution of this paper is to highlight the importance of competition within the household.

Bernheim et al. (1985) present a model in which strategic interactions between children play a prominent role. Specifically, they develop a model of intergenerational transfers in which parents influence the behavior of their children by threatening to disinherit them. Their model differs in two important ways from ours. First, they describe interactions between children as strategic but not competitive. The key intuition in their model is that threats of disinheritance are only credible when there is more than one child because with one child parents have no alternative allocation of inheritance. In contrast, our model explicitly addresses the idea that children compete with each other for resources from the parents: better own behavior leads to greater expected investment while better behavior of other children leads to lower expected investment. Second, their goal is to explain patterns in inheritance. Our model aims to capture parenting styles and envisions transfers as more instantaneous measures of parental investment. Focusing on this types of transfer may be a more realistic interpretation since Berhman and Rosenzweig (2004) find "that there are not significant sibling differences in bequests, despite the fact that the siblings differ significantly in their earning abilities and the amount of time they spend with parents prior to their parent."

The rest of the paper is organized as follows. Section 2 documents the main trends in economic opportunities for women, family size and parenting styles in the U.S. over the last century. Section 3 develops 
a simple noncooperative model of intra-household decisions that stresses the role of competition among family members in the determination of the distribution of resources within the household; particularly, in the surplus accrued to children and parenting styles. Section 4 extends the model in order to introduce corporal punishment. Section 5 concludes.

\section{Empirical Trends in Economic Opportunities for Women, Family Size and Parenting Styles}

This section documents the trends in economic opportunities for women, family size and parenting styles in the U.S. over the last century. To provide a concrete example of these differences consider two famous families from entertainment. Modern Family is a contemporary television show that depicts the life of Phil and Claire Dunphy and their three kids Haley, Alex and Luke. While Claire is a stay-at-home mom, she is also a former marketing executive for a big hotel chain and is largely in charge of keeping both the kids and her husband in line. Phil on the other hand is more of an overgrown child and "his main goal in life is to ensure that his kids and their friends see him as being cool." The relationships between these family members stand in stark contrast to those depicted in One Man's Family, a popular radio soap opera that aired between 1932 and 1959. The serial documented the life of Henry Barbour, his wife Fanny and their five children (Paul, Hazel, Clifford and Claudia, and Jack). Fanny, a housewife, and the five children were largely subservient to Henry, the family patriarch who ruled with an iron fist.

In the following subsections we document how the differences between these two families-at least with respect to the economic role of wives, the number of children and parenting styles-are representative national trends. We heavily rely on the work of other scholars but also build our own evidence from various sources. Since a key focus of our analysis is on how the relative earnings of the spouses and the number of children influence the distribution of resources between parents and children, we make a special effort to document that the trends apply to two parent households with children. Thus, when possible, we restrict the sample to households with married parents who both appear in the sample and have at least one child. ${ }^{1}$

\footnotetext{
${ }^{1}$ There are other important changes to family structure that occurred during this time period -notably the rise of single mothers in the second half of the 20th century. However, an analysis of these changes is outside the scope of this paper.
} 


\subsection{Economic Opportunities for Women}

Over the last century the earnings structure of the typical American household evolved from one in which the husband was the primary breadwinner to that of dual earner household. Figures 1 and 2 use U.S. census data to trace out changes in the labor force participation and the wife's contribution to household earnings. ${ }^{2}$ The measurement of labor force participation differs for years before and after 1940 and there is some debate as to how to compare the earlier and later data. The primary concern is that female labor force participation data from earlier periods suffer from measurement error because earnings from home production were not treated consistently. However, for the purposes of our argument we are more interested in mothers working for paid labor, and here the trends are much less controversial. In Understanding the Gender Gap, Claudia Goldin notes that while female employment is a somewhat ambiguous concept in the early $20^{\text {th }}$ century, "when the concept of labor force is restricted to work done for pay outside the home, participation rates for white married women increased continuously from 1890 to present." (Goldin 1992). Figures 1 and 2 clearly illustrate the transformational increases in the relative earning power of wives during the 20th century.

\footnotetext{
${ }^{2}$ The data are made available through Integrated Public Use Microdata Series (IPUMS) see Ruggles et al. (2015). In Figures 1-3 data for each year comes from 1\% samples of the U.S. census with two exceptions. Data from 1980 is from the $5 \%$ sample because the $1 \%$ sample was note available while data from 2010 is from 5 years of the ACS because the 2010 census does not have labor force participation data. The sample in each year contains husbands and wives with at least one child (individual under the age of 18) present in the household. Calculations in each year are competed using household weights provided through IPUMS.
} 
Figure 1: Labor Force Participation Rates

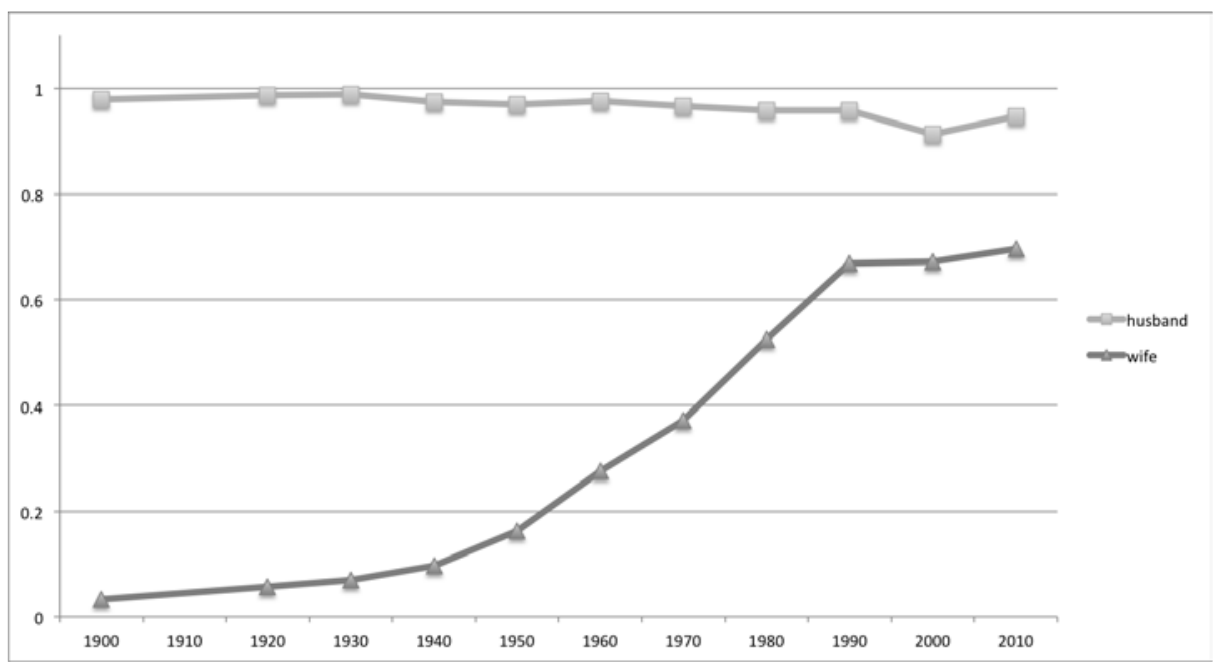

Note: Definition of labor force status is standardized across years starting in 1940. See

IPUMS documentation for detailed description of the variable in each year.

Figure 2: Distribution of Earnings Between Spouses

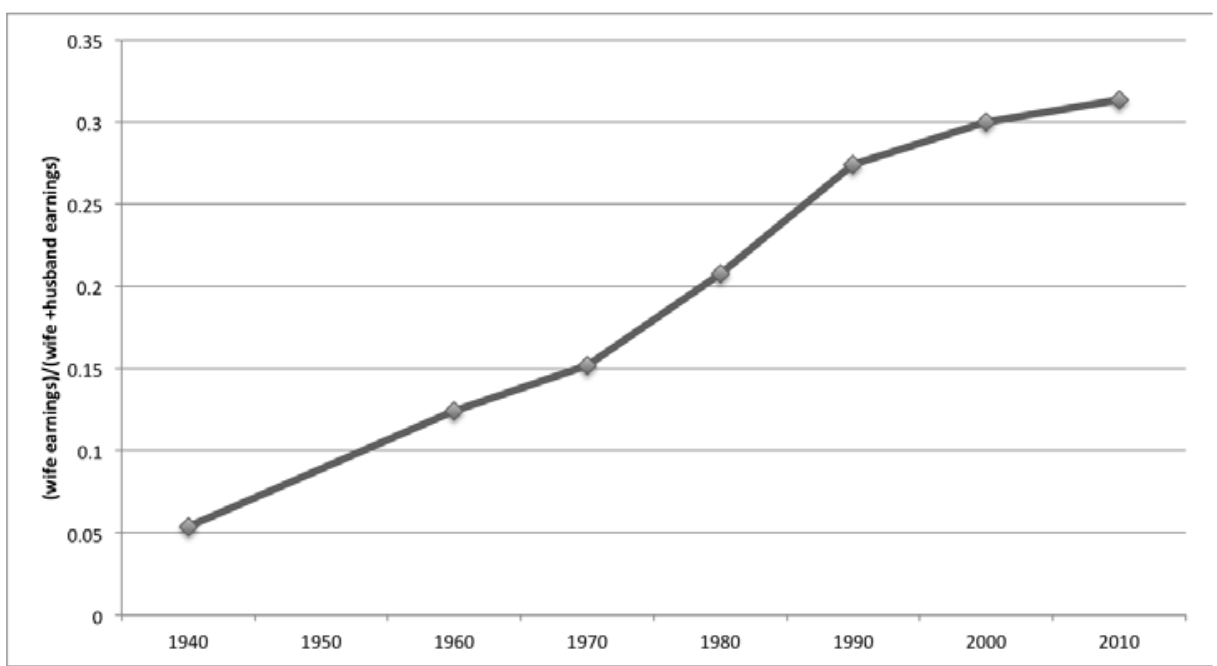

Note: Earnings are total pre-tax wage and salary income from the previous year. Households where either husband or wife are missing earnings data or both have zero earnings are dropped from the sample. 


\subsection{Family Size}

Compared to a century ago, families today also have fewer children. Figure 3 shows the evolution in the average number of children per household with at least one child. The average number of children per household declined by about 0.9 between 1900 and 2010. This pattern is consistent with the existing evidence in the demographic literature, which has documented sustained declines in fertility starting in the $19^{\text {th }}$ century (see, among others, Hacker 2003). Hobbs and Stoops (2002) use census data to document similar declines in family size and children per household in the $20^{\text {th }}$ century.

Figure 3: Average Family Size

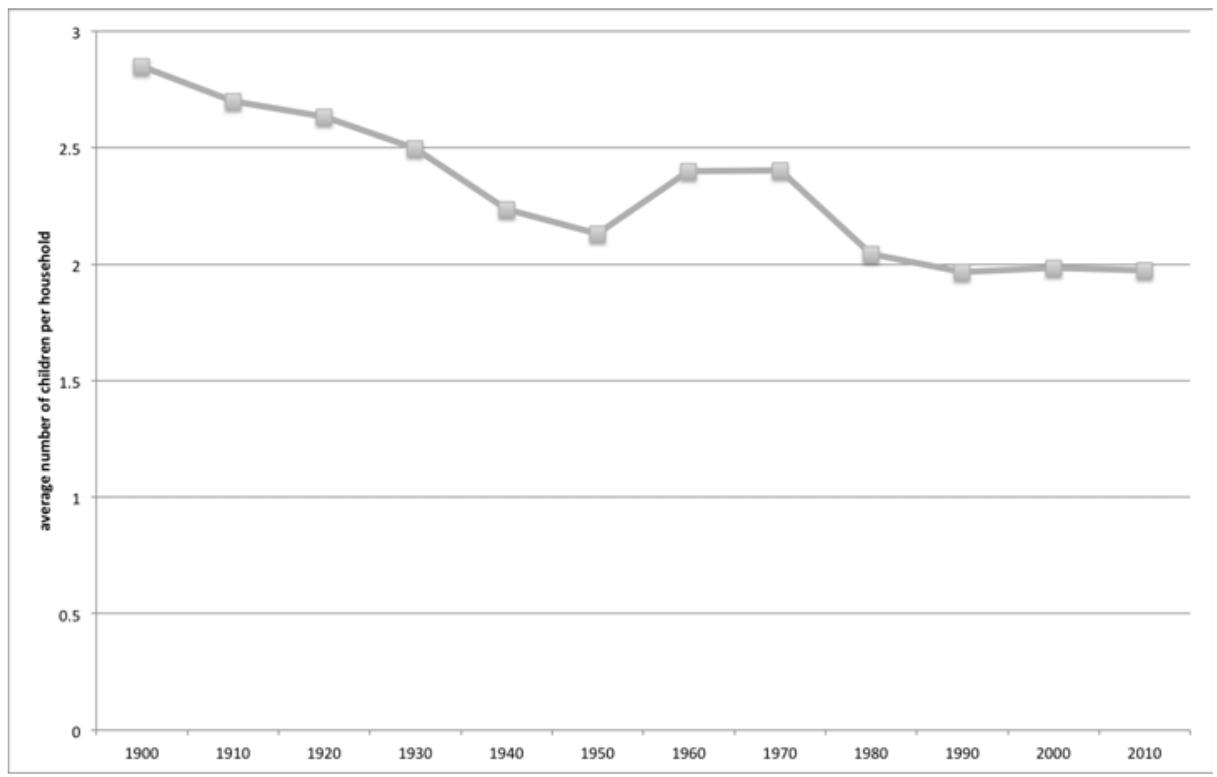

Note: number of children is the number of own children residing in the household.

\subsection{Parenting Styles}

Documenting trends in parenting styles is a difficult task. There is very little informative data collected in the early $20^{\text {th }}$ century and the relationship between children and their parents is complex and multifaceted. Thus, measurement error is likely to be a serious issue. Despite these challenges, we argue that there is convincing evidence of a systematic change in parenting styles over the last hundred years. To support this claim we draw from various sources to show trends related to: attitudes towards children, discipline methods, expenditure patterns and time use. All of the patterns strongly suggest that a shift within the 
household took place over the past century that has allowed children to capture a greater share of the household surplus.

A number of researchers have argued that general attitudes towards children have drastically changed during the $20^{\text {th }}$ century. For example, Stearns (2003) argues that over the last two centuries parents have changed "their ideas about children's nature, attributing to it a greater sense of vulnerability and frailty." Stearns supports these claims by citing parenting advice, developments in medicine (such as the focus on children's posture), views of organizations and articles in newspapers and magazines. In addition, he documents how these changes in attitudes have coincided with changes in behaviors providing examples such as: parental discipline methods, grade inflation, decline in child labor and a growing obsession of entertaining children. Zelizer (1985) paints a similar picture arguing that during the late 19th and early 20th century a new social construct emerged in which the child was "economically useless but emotionally priceless." This view is supported by the work of Duane Alwin who has conducted several studies of the changes in traits parents desire in their children. Employing data from Detroit Michigan from 1958 to 1983 , Middletown Indiana from 1924 to 1978, as well as nationally representative data from 1964 to 1984, Alwin (1988, 1990 and 1989) concludes that "child qualities generally thought to be associated with obedience or conformity (to obey parents, to have good manners, to be neat and clean, and to act according to sex-role norms) are seen to have declined in importance, and the qualities generally associated with autonomy or self-direction (good sense and sound judgment, honesty, responsible, and considerate) have increased in their assessed importance to parents during this period." The documented changes in attitudes suggest that parents have become increasingly attentive to the demands and desires of their children.

There is also evidence that suggests that parents have become less strict and discipline methods less severe. For example, we found two nationally representative surveys (from 1987 and 1995) in which parents were asked if they were more, less or equally as strict as their own parents. In both surveys, a greater percent of respondents said that they were less strict relative to their parents as opposed to more strict (see Figure 4). These views have also manifested in the attitudes towards corporal punishment. The General Social Survey (GSS) is a nationally representative survey that has collected parental attitudes towards discipline between 1986 and 2014 (see Smith et al. 2014). Specifically, the GSS asks parents if they agree that "it is sometimes necessary to discipline a child with a good, hard spanking?" Figure 
5 shows that the percent of parents that strongly agree or agree with this statement has declined from $84 \%$ in 1986 to $70 \%$ in 2014 . While there is no long-term series of representative data on the incidence of corporal punishment within the household, there are some data on the use of physical discipline measures in public schools. Gershoff et al. (2015) document a steady decline in corporal punishment in schools in the latter half of the $20^{\text {th }}$ century. Since 1970's 30 states have passed laws prohibiting the use of corporal punishment in schools (corporal punishment in public schools still remains legal in 19 states). Whether as a consequence of the laws or shifts in social norms, the prevalence of corporal punishment in schools dropped from $4 \%$ to $0.5 \%$ between 1978 and 2016 (Gershoff et al. 2015). Overall, the existing evidence indicates that, compared with previous generations, parents are more lenient towards their children and view physical punishment as a less acceptable form of discipline for children.

In addition to changes in discipline, parents are spending more money on their children. Kornrich and Furstenberg (2013) using data from the Consumer Expenditure Survey (CES) find that investment per child (in absolute terms and relative to overall consumption and income) has increased between 1972 and 2007. Part of this change is driven by the fact that children are taking longer to become financially independent (Danziger and Rouse 2007 and Furstenberg et al. 2004) and parents now allocate a significant portion of income to older children. For example, Schoeni and Ross (2005) document that parents allocate about $10 \%$ of their income to children older than 18 . However, not all of this increase is driven by later stage investments and Kornrich and Furtenberg (2013) note that "parents during the 1990s and 2000s spent earlier and extended their support for children into the later ages." Thus, by investing more money for longer periods of time, parents are increasingly allocating more financial resources to their children.

Lastly, parents are also spending more time with their children. Bryant and Zick (1996) study time use data of mothers in Indiana between the 1920's and the 1980's. They find that, despite declines in family size, mothers have increased the total time with children and, hence, time per child has markedly increased. Bianchi et al. (2006) conduct a thorough analysis of nationally representative time use data to study changes in parental behavior between 1965 and 2001. They find that married parents are spending more time with their children even though they are working longer hours. Figure 6 is taken from their study and shows that both married mothers and fathers have increased absolute time spent with children between 1975 and 2000. Some of this increase is made possible by a decline in housework 
duties. However, the authors also find that parents are increasingly multitasking and combining leisure with their children. Lareau (2003) document how today's parents organize their schedule around the activities of their children. In response, Bianchi et al. (2006) note that "this middle-class vision of intensive parental involvement in children's activities to ensure later success is spreading. It was not the norm, even for the middle class in 1965, the beginning point of our story. Lareau's parents do not recall this level of frenetic activity or level of parental involvement in their childhoods." The research discussed here indicates that parents are increasingly organizing their lives around the demands of their children.

Overall, the existing evidence on the evolution of parents' attitudes and behaviors suggest that the relationship between parents and children shifted over the last century. We are not arguing that parents loved their children less in the past. Indeed, the historical evidence suggests that parents have loved and cared for their children throughout time. ${ }^{3}$ We are, however, arguing that the nature of the parent child relationship -as seen in the allocation of resources (both time and money) within the household, the use of corporal punishment and general attitudes- did seem to change in a way that benefited children.

\footnotetext{
${ }^{3}$ There is extensive historical literature examining parenting styles in Western society. In 1960 Philippe Ariés published Centuries of Childhood in which he argued that there was no concept of childhood in the middle ages. While historians have widely denounced many of his claims, this work is credited with setting the agenda for research on childhood over the past half century. A decade later, a number of researchers-DeMause (1974), Shorter (1976), Stone (1977), Plumb (1975) and Trumbach (1978)-provided evidence of a shift in attitudes towards children sometime between 1500 and modern day. The specific details and interpretation presented by these authors differ, but they all agree that this shift lead to more affectionate relationships between children and their parents. This view came under fire in the 1980's starting with Pollock (1985). She studies over 400 journals and autobiographies written between 1500 and 1900 and finds little evidence of systematic change in attitudes towards children. Given the serious data constraints (which Pollock discusses in detail), a consensus on parenting styles before the $20^{\text {th }}$ century is unlikely to form. However, Hugh Cunningham (1995) reviews the existing literature and argues that, taken as a whole, the evidence does suggest that a shift in parenting styles took place over the last few centuries. He notes that while there are hints of this shift starting in the seventeenth century, the most drastic changes occurred in the $20^{\text {th }}$ century.
} 
Figure 4: Comparison of Parenting Style to Own Parents

1987

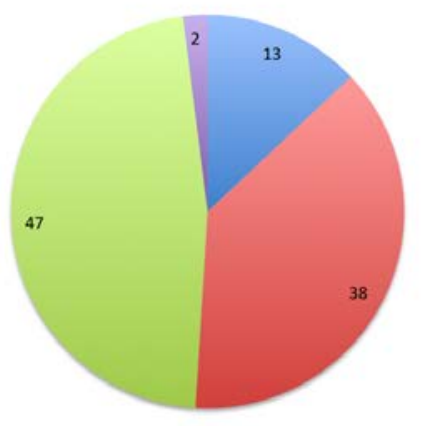

1995

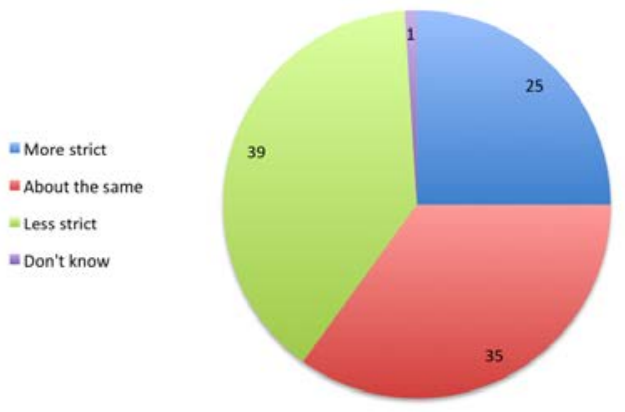

Note: Data from 1987 and 1995 are from the Parents Magazine Poll and Gallup Poll respectively.

Figure 5: Attitudes Towards Corporal Punishment in the Home

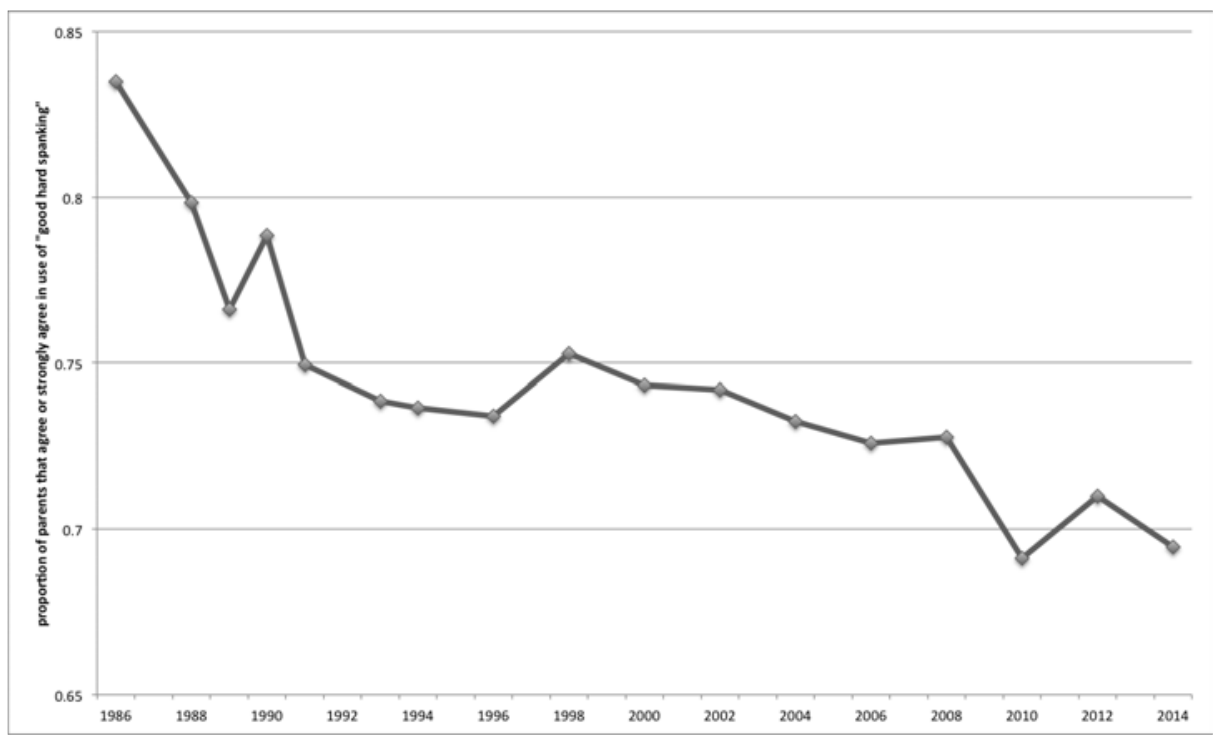

Note: Individual weights are applied to account for the fact that surveys are representative of households but only one adult per household responds. 
Figure 6: Total Weekly Hourse with Children

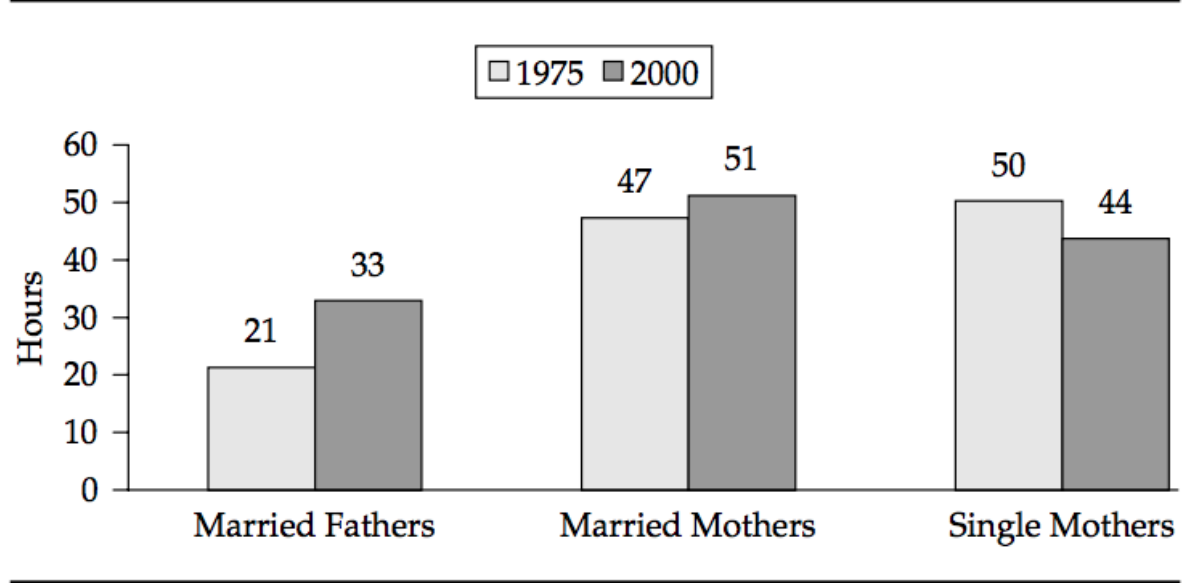

Source: Authors' calculations from the 1975-76 Time Use in Economic and Social Accounts and the combined file of the 1998-99 Family Interaction, Social Capital and Trends in Time Use Study and the 2000 National Survey of Parents.

Note: Difference between 2000 and 1975 estimates statistically significant at $\mathrm{p}<0.05$ for married fathers.

Note: Figure is taken from Changing Rhythms of American Family Life (Bianchi et al. 2006)

\subsection{Summary of Empirical Trends}

In this section we have documented three trends that occurred over the course of the $20^{\text {th }}$ century: (1) wives entered the labor force and their contribution to household income rose dramatically, (2) the average number of children per household declined and (3) a shift in parenting styles-as seen in changes in the allocation of resources (both time and money) within the household, the use of corporal punishment and general attitudes-that allowed children to capture a greater share of the household surplus. We argue that there is a casual link between the first two trends and the changes in parenting styles. In the next section we develop a formal model of parenting styles in which competition between family members plays a central role in mediating this relationship.

\section{A Simple Noncooperative Model of Intra-household Decisions}

This section develops a model of intra-household decisions that capture parenting styles. Consider a household with two parents indexed by $p \in\{m, f\}$ and $N \geq 1$ children who are indexed by $c \in\{1, \ldots, N\}$. 
Let $y^{p}$ denote the income of parent $p, x^{p}$ his or her contribution to the material household consumption, $i^{p}$ his or her material investment to influence the behavior of the children, and $b^{p}$ the behavior of the children toward parent $p$. The budget constraint of parent $p$ is $x^{p}+i^{p}=y^{p}$ and $p$ 's utility is given by:

$$
u^{p}=\left(\frac{x^{p}+\beta_{x} x^{-p}}{1+\beta_{x}}\right)^{\alpha_{x}}\left(b^{p}\right)^{\alpha_{b}},
$$

where $\alpha_{x}>0, \alpha_{b}>0$ and $\alpha_{x}+\alpha_{b}=1$. The first term captures the value of material consumption and indicates that material consumption is partially a public good. The parameter $\beta_{x} \in[0,1]$ governs the extent to which material consumption is a public good where $\beta_{x}=1\left(\beta_{x}=0\right)$ represents a purely public (private) good. The second term captures the behavior of the children toward parent $p$. As will be discussed below, $b^{p}$ will depend on the number of children $N$ as well as the investments made by each parent to influence the behavior of the children $\left(i^{p}\right.$ and $\left.i^{-p}\right)$.

Parents influence the behavior of the children by using a first-price auction to divide their material investments among the $N$ children. ${ }^{4}$ Children submit bids that are interpreted as proposed levels of behavior. The idea is that children and parents have different preferences over the behavior of the children and by submitting higher bids, children agree to behave closer to the behavior preferred by the parents. As we will see, the children are willing to offer better behavior in return for higher levels of investments. The auction framework allows us to capture the idea that the household is an environment in which individuals compete with each other over limited resources. In particular, assume that the behavior of the children toward parent $p$ is given by:

$$
b^{p}=\sum_{c=1}^{N} \frac{\mathbf{E}\left(b_{p}^{c}\right)+\beta_{b} \mathbf{E}\left(b_{-p}^{c}\right)}{1+\beta_{b}}
$$

where $\mathbf{E}\left(b_{p}^{c}\right)$ is the expected behavior of child $c$ in the auction run by parent $p$ and $\sum_{c=1}^{N} \mathbf{E}\left(b_{p}^{c}\right)$ is the expected behavior of the children in the auction of parent $p$ (this is just the expected revenue from the auction). Note that $\beta_{b} \in[0,1]$, which means that the behavior of the children is in part a public good, but each parent cares relatively more about the behavior of the children in his or her own auction. We interpret this as parents having, to some extent, different preferences over the behavior of the children. For example, both parents benefit when the children put more effort at school regardless of which parent

\footnotetext{
${ }^{4}$ We have also solved the model using an all-pay auction with no reserve price. The main results hold, but we require that $N \geq 2$.
} 
is inducing such behavior. At the same time, the love and respect of a child could be more of a private good for each parent.

The timing of events is as follows: (1) Investment. Parents choose investment levels and reservation prices in each auction. (2) Auction. For each auction, children's valuations are realized and they simultaneously and independently submit bids. The investment is allocated to the highest bidder and the highest bidder pays his or her bid to the parent.

Let $v_{p}^{c} \in\left[0, i^{p}\right]$ be the valuation that child $c$ gives to $i^{p}$ units of investment in $p$ 's auction. Assume that $v_{p}^{c}$ is independently and identically distributed and follows a uniform distribution on $\left[0, i^{p}\right]$. Child $c$ observes his or her valuation but only knows that other siblings' values are independently and uniformly distributed on $\left[0, i^{p}\right]$. Let $b_{p}^{c} \in\left[0, i^{p}\right]$ denote the behavior that child $c$ bids in $p$ 's auction and suppose that parent $p$ sets a reserve price equal to $r^{p} \in\left[0, i^{p}\right]$. Then, the utility that child $c$ obtains from $p$ 's auction is given by:

$$
u_{p}^{c}= \begin{cases}v_{p}^{c}-b_{p}^{c} & \text { if } b_{p}^{c}>\max _{j \neq c}\left\{b_{p}^{j}, r^{p}\right\}, \\ 0 & \text { if } b_{p}^{c}<\max _{j \neq c}\left\{b_{p}^{j}, r^{p}\right\} .\end{cases}
$$

We assume that the total utility of the child is simply the sum of the expected payoffs from each auction, i.e.,

$$
u^{c}=\mathbf{E}\left(u_{m}^{c}\right)+\mathbf{E}\left(u_{f}^{c}\right)
$$

\section{Equilibrium Analysis}

This section characterizes the equilibrium. We proceed through backward induction. First, we study the equilibrium in the auctions among children and use the notion of symmetric Bayesian Nash equilibrium. Second, given the equilibrium payoffs in the auction stage, we characterize the Nash equilibrium investments by the parents. Since the goal of the model is to explore how changes in the family size and the relative earnings of the spouses influence the distribution of resources within the household, at end of each stage of the backward induction procedure we discuss how household size and the relative income of the spouses affect the equilibrium. 


\subsection{Competition Among Siblings}

When choosing their bids, children know their own valuation and the distribution of the valuations of their siblings. The following proposition characterizes the bid function equilibrium of the auction stage, the expected payoff of each child and the expected level of behavior derived from each auction.

Proposition 1 Competition among siblings. The symmetric Bayesian Nash equilibrium bid function in the auction of parent $p$ is given by:

$$
b\left(v_{p}^{c}\right)=\frac{(N-1) v_{p}^{c}+\left(r^{p}\right)^{N}\left(v_{c}^{p}\right)^{1-N}}{N} \text { for } v_{c}^{p} \in\left[r^{p}, i^{p}\right] .
$$

The equilibrium expected behavior of the children in the auction of parent $p$ is given by:

$$
\sum_{c=1}^{N} \mathbf{E}\left(b_{p}^{c}\right)=\frac{(N-1)\left(i^{p}\right)^{N+1}+(N+1)\left(r^{p}\right)^{N} i^{p}-2 N\left(r^{p}\right)^{N+1}}{\left(i^{p}\right)^{N}(N+1)},
$$

while the equilibrium expected payoff of a child in the action of parent $p$ is given by:

$$
\mathbf{E}\left(u_{p}^{c}\right)=\frac{\left(i^{p}\right)^{N+1}-(N+1)\left(r^{p}\right)^{N} i^{p}+N\left(r^{p}\right)^{N+1}}{\left(i^{p}\right)^{N} N(N+1)} .
$$

Moreover, if parents can select any reserve price, in equilibrium, both choose $r^{p}=i^{p} / 2$. Then:

$$
\sum_{c=1}^{N} \mathbf{E}\left(b_{p}^{c}\right)\left(r^{p}=i^{p} / 2\right)=f(N) i^{p} \text { and } \mathbf{E}\left(u_{p}^{c}\right)\left(r^{p}=i^{p} / 2\right)=g(N) i^{p},
$$

where $f(N)=\frac{(N-1)(2)^{N}+1}{(N+1)(2)^{N}}$ and $g(N)=\frac{(2)^{N+1}-(N+2)}{(2)^{N+1} N(N+1)}$. Proof: see the Appendix.

Note that the bid function is increasing in the number of siblings. Formally, the derivative of $b\left(v_{p}^{c}\right)$ with respect to $N$ is given by:

$$
\frac{\partial b\left(v_{p}^{c}\right)}{\partial N}=\frac{\left(r^{p}\right)^{N}\left(v_{c}^{p}\right)^{1-N}}{N^{2}}\left[\left(\frac{v_{c}^{p}}{r^{p}}\right)^{N}-\ln \left(\frac{v_{c}^{p}}{r^{p}}\right)^{N}-1\right]>0 .
$$

Thus, more children in the household lead to greater competition, which raises the bids offered by each child. Moreover, higher bids induce a lower expected payoff for each child, but better expected behavior as experienced by the parent running the auction. Formally, the derivative of $\mathbf{E}\left(u_{p}^{c}\right)$ with respect to $N$ is given by: 


$$
\frac{\partial \mathbf{E}\left(u_{p}^{c}\right)}{\partial N}=\left\{\frac{-(2 N+1)\left(\frac{i^{p}}{r^{p}}\right)^{N+1}+\left(\frac{i^{p}}{r^{p}}\right)(N+1)^{2}\left[1+\ln \left(\frac{i^{p}}{r^{p}}\right)^{N}\right]-N^{2}\left[1+\ln \left(\frac{i^{p}}{r^{p}}\right)^{N+1}\right]}{N^{2}(N+1)^{2}\left(\frac{i^{p}}{r^{p}}\right)^{N}}\right\} r^{p}<0,
$$

while the derivative of $\sum_{c=1}^{N} \mathbf{E}\left(b_{p}^{c}\right)$ with respect to $N$ is given by:

$$
\frac{\partial \sum_{c=1}^{N} \mathbf{E}\left(b_{p}^{c}\right)}{\partial N}=\left\{\frac{2\left(\frac{i^{p}}{r^{p}}\right)^{N+1}-(N+1)^{2}\left(\frac{i^{p}}{r^{p}}\right) \ln \left(\frac{i^{p}}{r^{p}}\right)-2(N+1)+2 N\left[1+\ln \left(\frac{i^{p}}{r^{p}}\right)^{N+1}\right]}{(N+1)^{2}\left(\frac{i^{p}}{r^{p}}\right)^{N}}\right\} r^{p}>0 .
$$

Bids are also higher when the investment available in auction $p$ is higher. Two mechanism are behind this result. First, for a given reverse price, the distribution of valuations for a higher $i^{p}$ first order stochastically dominates the distribution of valuations for a lower $i^{p}$. (Recall the valuations are uniformly distributed on the interval $\left[0, i^{P}\right]$.) This induces children to increase their bids when $i^{p}$ rises. Second, bids are increasing in the reserve price, which strengthens the effect of investment on bids since, in equilibrium, the reserve price is increasing in investment. Thus, children offer better behavior in return for higher rewards. Formally, $\sum_{c=1}^{N} \mathbf{E}\left(b_{p}^{c}\right)\left(r^{p}=i^{p} / 2\right)=f(N) i^{p}$ and $\mathbf{E}\left(u_{p}^{c}\right)\left(r^{p}=i^{p} / 2\right)=g(N) i^{p}$ are both increasing in $i^{P}$.

Summing up, the expected bevahior of the children in the auction of parent $p$ is increasing in the number of children and investment while the expected payoff of a child is decreasing in the number of children but increasing in investment.

\subsection{Competition Between Parents}

Parents know the distribution of the children's valuations and, hence, they can anticipate the equilibrium of the auction stage. Thus, employing Proposition 1, parent $p$ expected utility can be rewritten as follows:

$$
u^{p}=\left[\frac{y^{p}-i^{p}+\beta_{x}\left(y^{-p}-i^{-p}\right)}{1+\beta_{x}}\right]^{\alpha_{x}}\left[\frac{f(N)\left(i^{p}+\beta_{b} i^{-p}\right)}{1+\beta_{b}}\right]^{\alpha_{b}} .
$$

Each parent chooses a level of investment to maximize his or her own expected utility, taking the investment of the other spouse as given. A Nash equilibrium is a pair of investment decisions of the mother and father that are mutual best responses. 
We make two simplifying assumptions. First, without loss of generality, we assume that $y^{f} \geq y^{m}>0$. Second, we assume that $\beta_{x}<\alpha_{x}<\alpha_{b} / \beta_{b}$. As we shall see, the second assumption states that there are not large asymmetries regarding how parents value material consumption and the behavior of their children. The assumption guarantees that there is no equilibrium in which both parents play a corner solution. The following proposition fully characterizes the equilibrium investment choices.

Proposition 2 Competition between parents. Suppose that $y^{f} \geq y^{m}>0$ and $\beta_{x}<\alpha_{x}<\alpha_{b} / \beta_{b}$.

1. If $\beta_{b}>\beta_{x}$, then, the Nash equilibrium levels of investments are given by:

$$
i^{m}=\left\{\begin{array}{ll}
i^{m, *} & \text { if } y^{m} / y^{f}>\bar{y}^{r}, \\
0 & \text { if } y^{m} / y^{f} \leq \bar{y}^{r} .
\end{array} i^{f}= \begin{cases}i^{f, *} & \text { if } y^{m} / y^{f}>\bar{y}^{r} \\
\alpha_{b}\left(y^{f}+\beta_{x} y^{m}\right) & \text { if } y^{m} / y^{f} \leq \bar{y}^{r}\end{cases}\right.
$$

2. If $\beta_{b}<\beta_{x}$, then, the Nash equilibrium levels of investments are given by:

$$
i^{m}=\left\{\begin{array}{ll}
i^{m, *} & \text { if } y^{m} / y^{f}>\hat{y}^{r}, \\
y^{m} & \text { if } y^{m} / y^{f} \leq \hat{y}^{r} .
\end{array} i^{f}= \begin{cases}i^{f, *} & \text { if } y^{m} / y^{f}>\hat{y}^{r}, \\
\alpha_{b} y^{f}-\alpha_{x} \beta_{b} y^{m} & \text { if } y^{m} / y^{f} \leq \hat{y}^{r}\end{cases}\right.
$$

where:

$$
\begin{aligned}
i^{m, *} & =\alpha_{b}\left[\left(\delta_{1}-\delta_{2} \beta_{x}\right) y^{m}+\left(\delta_{1} \beta_{x}-\delta_{2}\right) y^{f}\right], i^{f, *}=\alpha_{b}\left[\left(\delta_{1}-\delta_{2} \beta_{x}\right) y^{f}+\left(\delta_{1} \beta_{x}-\delta_{2}\right) y^{m}\right], \\
\bar{y}^{r} & =\frac{\alpha_{x}\left(\beta_{b}-\beta_{x}\right)}{\alpha_{x}\left(1-\beta_{b} \beta_{x}\right)+\alpha_{b}\left(1-\beta_{x} \beta_{x}\right)}, \hat{y}^{r}=\frac{\left(\beta_{x}-\beta_{b}\right) \alpha_{b}}{1-\left(\alpha_{b} \beta_{x}+\alpha_{x} \beta_{b}\right) \beta_{b}}, \\
\delta_{1} & =\frac{1}{1-\left(\alpha_{b} \beta_{x}+\alpha_{x} \beta_{b}\right)^{2}}, \delta_{2}=\frac{\alpha_{b} \beta_{x}+\alpha_{x} \beta_{b}}{1-\left(\alpha_{b} \beta_{x}+\alpha_{x} \beta_{b}\right)^{2}} .
\end{aligned}
$$

Proof: see the Appendix.

Proposition 2 shows that the competition between the parents can adopt two forms. When $\beta_{b}>\beta_{x}$, for more traditional families $\left(y^{m} / y^{f} \leq \bar{y}^{r}\right)$ only the father influences the behavior of the children, while for more modern families $\left(y^{m} / y^{f}>\bar{y}^{r}\right)$ both parents influence the behavior of the children. The intuition is as follows. When $\beta_{b}>\beta_{x}$, the public good component of the behavior of the children is dominant. Thus, if the mother is relatively poor with respect to the father, she prefers to free ride off the the father's investment. On the contrary, when $\beta_{b}<\beta_{x}$, the rivalry between the parents is dominant. The behavior 
of the children becomes predominantly a contest between the parents. In this case, in traditional families $\left(y^{m} / y^{f} \leq \hat{y}^{r}\right)$, the mother invests all her income in the children, while in modern families $\left(y^{m} / y^{f}>\hat{y}^{r}\right)$ both parents actively dispute to influence the behavior of the children.

The following corollary describes how parental income, $\beta_{x}$ and $\beta_{b}$ all interact to determine the share of resources that children are able to capture.

Corollary 1 Investment shares. Under the assumptions in Proposition 2.

1. If $\beta_{b}>\beta_{x}$, then:

$$
\frac{i^{m}+i^{f}}{y^{m}+y^{f}}= \begin{cases}\alpha_{b}\left(1+\beta_{x}\right)\left(\delta_{1}-\delta_{2}\right) & \text { if } y^{m} / y^{f}>\bar{y}^{r} \\ \frac{\alpha_{b}\left(y^{f}+\beta_{x} y^{m}\right)}{y^{m}+y^{f}} & \text { if } y^{m} / y^{f} \leq \bar{y}^{r}\end{cases}
$$

where $\left(i^{m}+i^{f}\right) /\left(y^{m}+y^{f}\right)$ is weakly decreasing in $y^{m} / y^{f}$.

2. If $\beta_{b}<\beta_{x}$, then:

$$
\frac{i^{m}+i^{f}}{y^{m}+y^{f}}= \begin{cases}\alpha_{b}\left(1+\beta_{x}\right)\left(\delta_{1}-\delta_{2}\right) & \text { if } y^{m} / y^{f}>\hat{y}^{r}, \\ \frac{\alpha_{b} y^{f}+\left(1-\alpha_{x} \beta_{b}\right) y^{m}}{y^{m}+y^{f}} & \text { if } y^{m} / y^{f} \leq \hat{y}^{r} .\end{cases}
$$

where $\left(i^{m}+i^{f}\right) /\left(y^{m}+y^{f}\right)$ is weakly increasing in $y^{m} / y^{f}$.

Proof: see the Appendix.

When $\beta_{b}>\beta_{x}$, the behavior of the children is relatively more of a public good. Thus when $y^{m} / y^{f}<\bar{y}^{r}$ the husband increases his investment in the children when his wife's income increases. However, his increase in investment only accounts for his own utility while his wife continues to invest nothing in the children. Thus, the share of resources allocated towards the children decreases as the income gap between mother and father decreases. When $\beta_{b}<\beta_{x}$, more equal income between parents allows the children to capture a larger portion of the surplus. This prediction is better aligned with the historical evidence. In this case the behavior of the children is more of a private good. Thus, when $y^{m} / y^{f}<\hat{y}^{r}$ the wife will choose to free-ride off of the husband's contributions to household material goods while both the husband and wife will choose to compete for the behavior of the children. As the income of the wife increases, she has more resources available to her to invest in the children. Thus, closing the gap between male and female earnings will results in more resources allocated to the children. 


\subsection{Distribution within the Household}

The following corollary summarizes how the income of the household, the ratio of the income of the spouses and the number of children affect the distribution of payoffs within the household.

Corollary 2 Distribution within the Household. Under the assumptions in Proposition 2. In addition, assume that $\beta_{b}<\beta_{x}$ and $y^{m} / y^{f} \leq \hat{y}^{r}$. Then:

1. $N u^{c} / u^{f}$ is independent of $\left(y^{m}+y^{f}\right)$, increasing in $y^{m} / y^{f}$ and decreasing in $N$ for $N \geq 3$. Moreover, there exists $\bar{\alpha}_{b}$ such that if $\alpha_{b} \geq \bar{\alpha}_{b}$, then $N u^{c} / u^{f}$ is independent of $\left(y^{m}+y^{f}\right)$, decreasing in $N$ for all $N \geq 1$.

2. $N u^{c} / u^{m}$ is independent of $\left(y^{m}+y^{f}\right)$, decreasing in $y^{m} / y^{f}$ for $y^{m} / y^{f} \leq \tilde{y}^{r}$ and increasing for $\tilde{y}^{r} \leq y^{m} / y^{f} \leq \hat{y}^{r}$, and decreasing in $N$ for $N \geq 3$. Moreover, there exists $\bar{\alpha}_{b}$ such that if $\alpha_{b} \geq \bar{\alpha}_{b}$, then $N u^{c} / u^{f}$ is decreasing in $N$ for all $N \geq 1$.

3. $u^{m} / u^{f}$ is increasing in $y^{m} / y^{f}$ and does not depend on $\left(y^{m}+y^{f}\right)$ or $N$. Proof: see the Appendix.

Corollary 2 summarizes the three most important predictions of the model. First, the total household income does not effect the distribution of surplus. This highlights the fact that the baseline model abstracts from income effects and focuses on the role of competition. Mechanically, this result is driven by the assumption of homothetic preferences of parents and children. We can extend the model to incorporate income effects and in the following section we explore the interaction between total household income and discipline. Second, as the income-gap between the spouses closes, children improve their position relative to the father $\left(N u^{c} / u^{f}\right.$ increases with $\left.y^{m} / y^{f}\right)$ and possibly also relative to the mother $\left(N u^{c} / u^{m}\right.$ increases with $y^{m} / y^{f}$ when $\tilde{y} \leq y^{m} / y^{f} \leq \hat{y}$ ). Third, as the number of siblings declines the combined utility of all children increases relative to each parents utility. In other words, in modern advanced societies with few kids and relatively more equal distribution of earnings between the parents, children are the rulers of the family. 


\section{Extension: Punishment}

Beside investments (carrots), parents can also employ punishment (sticks) in order to influence the behavior of the children. Suppose that before parents decide their investment levels, the father has the ability to impose punishment to the children. Assume that the utility of parent $p$ augmented with punishment is given by:

$$
u^{p}=\left[\frac{y^{p}-i^{p}+\beta_{x}\left(y^{m}-i^{m}\right)}{1+\beta_{x}}\right]^{\alpha_{x}}\left(b^{p}\right)^{\alpha_{b}}(e)^{-c_{z}^{p} z},
$$

where $z$ is the punishment that the father chooses to inflict upon the children and $c_{z}^{p}>0$ is the marginal cost of inflicting punishment for parent $p$. Note that, ceteris paribus, parents would rather not punish their children since they themselves suffer from the use of punishment. However, punishment is a tool that could be used to influence the behavior of the children. In particular, assume that the behavior of the children toward parent $p$ is given by:

$$
b^{p}=\frac{\sum_{c=1}^{N}\left[\mathbf{E}\left(b_{p}^{c}\right)+\beta_{b} \mathbf{E}\left(b_{-p}^{c}\right)\right]+\left[\chi^{p}+\left(1-\chi^{p}\right) \beta_{b}\right](N)^{\gamma}(z)^{1-\gamma}}{1+\beta_{b}},
$$

where $\chi^{p}=1$ if $p=f$ and $\chi^{p}=0$ if $p=m$ and $\gamma \in(0,1)$. Note that the marginal effect of $z$ on $b^{p}$ is increasing in the number of children, which captures the idea that it is more effective for the parents to influence the behavior of the children through punishment when they have more children (for example, when one child is punished, parents establish a reputation with other children). Finally, assume that the utility of child $c$ augmented with punishment is given by

$$
u^{c}=\mathbf{E}\left(u_{m}^{c}\right)+\mathbf{E}\left(u_{f}^{c}\right)-c_{z}^{c} z
$$

where $c_{z}^{c}>0$ is the marginal cost of the punishment suffered by child $c$.

The following proposition characterizes the equilibrium punishment and investment levels.

Proposition 3 Suppose that $y^{m} / y^{f} \leq \hat{y}^{r}, \quad \beta_{b}<\beta_{x}<\alpha_{x}<\alpha_{b} / \beta_{b}$ and $\bar{z}=$ $\left[\frac{\alpha_{b} f(N)}{\alpha_{x}(N)^{\gamma}}\right]^{\frac{1}{1-\gamma}}\left(y^{f}-\frac{\alpha_{x} \beta_{b}}{\alpha_{b}} y^{m}\right)^{\frac{1}{1-\gamma}}$. Then, the Nash equilibrium levels of investments and punishment are 
given by:

$$
\begin{aligned}
& i^{m}=y^{m}, i^{f}=\alpha_{b} y^{f}-\alpha_{x} \beta_{b} y^{m}-\alpha_{x}[f(N)]^{-1}(N)^{\gamma}(z)^{1-\gamma}, \\
& z= \begin{cases}\bar{z} & \text { if } \frac{(1-\gamma)(N)^{\gamma}}{f(N)\left(y^{f}+\beta_{b} y^{m}\right)\left(\bar{z}^{f}\right)^{\gamma}+(N)^{\gamma}\left(\bar{z}^{f}\right)} \geq c_{z}^{f}, \\
z^{*} & \text { if } \frac{(1-\gamma)(N)^{\gamma}}{f(N)\left(y^{f}+\beta_{b} y^{m}\right)\left(\bar{z}^{f}\right)^{\gamma}+(N)^{\gamma}\left(\bar{z}^{f}\right)} \leq c_{z}^{f},\end{cases}
\end{aligned}
$$

where $z^{*}$ is the unique solution to:

$$
\frac{(1-\gamma)(N)^{\gamma}}{f(N)\left(y^{f}+\beta_{b} y^{m}\right)\left(z^{*}\right)^{\gamma}+(N)^{\gamma}\left(z^{*}\right)}=c_{z}^{f}
$$

Proof: see the online appendix.

Several remarks apply. First, Proposition 3 expands the analysis of Proposition 2 when $\beta_{b}<\beta_{x}$ and $y^{m} / y^{f} \leq \hat{y}^{r}$, the region of the parameter space for which more equal income between spouses lead to a larger portion of the surplus allocated to the children. Second, investment (carrots) and punishment (sticks) are substitute inputs to produce good behavior. Indeed, as $z$ increases, $i^{f}$ decreases. Third, the father determines his optimal punishment level equalizing the marginal benefit of punishment with the marginal cost of punishment $c_{z}^{f}$. The marginal benefit of punishment for the father has two components. There is a direct effect of punishment on the behavior of the children and there is an indirect effect given by the impact of punishment on investment. As the father selects a higher level of punishment he invests less because carrots and sticks are substitute inputs. More importantly, the marginal benefit of punishment is affected by the income of each parent and the size of the household. The following corollary explores how equilibrium punishment changes with household income, the ratio of the spouses income and the number of children. It also shows that the introduction of punishment does not affect the key results deduced in Section 3.

Corollary 3 Under the assumptions in Proposition 3.

1. $z^{*}$ is decreasing in $\left(y^{f}+y^{m}\right)$, increasing in $y^{m} / y^{f}$, and increasing (decreasing) in $N$ if $\eta_{f, N}<\gamma$ $\left(\eta_{f, N}>\gamma\right)$.

2. $\left(i^{f}+i^{m}\right) /\left(y^{f}+y^{m}\right)$ is increasing in $y^{m} / y^{f}$.

Proof: see the online appendix. 
Corollary 3 provides three interesting new predictions. First, poorer families use punishment more intensively. The reason is that parents in poor families have fewer resources available to incentivize the children to behave well. Thus, they must resort to threat of punishment in order to influence the behavior of their children. This is similar to the intuition presented in Weinberg (2001). Second, as the gap between spousal earnings closes, the use of punishment is more likely. The reason is that the father has less income to influence the children and, hence, he is more willing to employ punishment. Third, larger families are more likely to use punishment when the elasticity of the expected behavior of the children in the auctions with respect to the number of children is relatively low. Finally, it is worth noting that introducing punishment into the model does not affect the key prediction that as the gap between male and female earnings closes more resources are allocated to the children.

\section{Conclusion}

In this paper we have developed a novel model of parenting and used it to explain the connection between improvements in economic opportunities for women, declines in family size and shifts in parenting styles over the course of the $20^{\text {th }}$ century. We have argued that the rise in the relative earnings of wives increased competition between spouses for influencing the behavior of the children while the decline in family size reduced competition between children for resources from their parents. The combined effect improved the position of children within the household and allowed them to capture an increasing share of the household surplus over the past hundred years. In addition, we extended the model to incorporate punishment. We argued that an increase in total household income and a decrease in family size would reduce the use of punishment while a reduction in the earnings gap between husband and wife would increase the use of punishment. Empirically, we observe that the use of corporal punishment declined and we thus posit that the former two effects dominated the latter.

The main contribution of this paper is to highlight the importance of competition within the household. To date, there is very little academic work on this topic but there are good reasons to think that it plays an important role. For example, biological research has argued that within family competition explains a broad range of phenomenon including: begging behavior of birds (see Harper 1986), aggression of fig wasps (see West et al. 2001) and siderophre production in pathogenic bacteria (see Griffin et al. 
2004). In addition, within family rivalries have appeared countless times in the arts (Shakespeare's King Lear offers a clear example). These forces are even present in religious texts. In the bible sibling rivalry plays out in a violent fashion between the first sons of mankind: Cain and Abel. Thus it seems reasonable to expect that competition within the household should shape behavior in meaningful ways.

Our effort to understand changes in parenting styles is largely motivated by the extensive empirical literature that documents the importance of parental inputs in determining long-term outcomes. Recent advances in our understanding of the skills formation process have pushed researchers to develop nuanced models of parent-child interactions. One important task of this literature is to explain the observed heterogeneity in parenting styles across time and space. We have argued that competition within the household is a useful concept for understanding this heterogeneity.

There are several promising routes to explore using the approach in this paper. First, it would be interesting to incorporate the different family structures that have become more common over the course

of the $20^{\text {th }}$ century. For example, one could introduce divorce in our model and study how competition between divorced parents affects the surplus obtained by the children. Second, since parenting styles are correlated with demographic and economic characteristics that are also associated with residential clustering, it may be productive to explore how parenting styles interact with the styles of other families in the community. For example, it is possible that more lenient parents produce a negative externality on their peers, who will find it more complicated to incentivize their children. Finally, since the economic literature on parenting styles is often motivated with concerns related to economic mobility, it would be interesting to extend this model to integrate external economic forces as well as the internal forces emphasized in this paper.

\section{References}

[1] Akabayashi, Hideo. 2006. An equilibrium model of child maltreatment. Journal of Economic Dynamics and Control 30(6): 993-1025.

[2] Alwin, Duane F. 1988. From Obedience to Autonomy: Changes in Traits Desired in Children, 19241978. The Public Opinion Quarterly 52(1): 33-52. 
[3] Alwin, Duane F. 1989. Changes in Qualities Valued in Children in the United States, 1964 to 1984. Social Science Research 18: 195-236.

[4] Alwin, Duane F. 1990. Cohort Replacement and Changes in Parental Socialization Values. Journal of Marriage and Family 52(2): 347-60.

[5] Ariés, Philippe. 1960. Centuries of Childhood. Harmondsorth.

[6] Becker, Gary S. 1974. A Theory of Social Interactions. Journal of Political Economy 82(6): 1063-093.

[7] Becker, Gary S., and Nigel Tomes. 1979. An Equilibrium Theory of the Distribution of Income and Intergenerational Mobility. Journal of Political Economy 87(6): 1153-189.

[8] Becker, Gary S., and Nigel Tomes. 1986. Human Capital and the Rise and Fall of Families. Journal of Labor Economics 4(3): S1-S39.

[9] Bernheim, B. Douglas, Andrei Shleifer, and Lawrence H. Summers. 1985. The Strategic Bequest Motive. Journal of Political Economy 93(6): 1045-076.

[10] Behrman, Jere R., Robert A. Pollak, and Paul Taubman. 1982. Parental Preferences and Provision for Progeny. Journal of Political Economy 90(1): 52-73.

[11] Behrman, Jere R., and Mark R. Rosenzweig. 2004. Parental Allocations to Children: New Evidence on Bequest Differences among Siblings. The Review of Economics and Statistics 86(2): 637-40.

[12] Bianchi, Suzanne M., John P. Robinson and Melissa A. Milke. 2006. The Changing Rhythms of American Family Life. New York: Russell Sage Foundation, 2006.

[13] Burton, Peter, Shelley Phipps, and Lori Curtis. 2002. All in the Family: A Simultaneous Model of Parenting Style and Child Conduct. The American Economic Review 92(2): 368-72.

[14] Bryant, W. Keith, and Cathleen D. Zick. 1996. Are we investing less in the next generation? Historical trends in time spent caring for children. Journal of Family and Economic Issues 17(3-4): 365-392.

[15] Chiappori, Pierre-André. 1992. Collective Labor Supply and Welfare. Journal of Political Economy 100(3): 437-67. 
[16] Cosconati, Marco. 2009. Parenting style and the development of human capital in children. Unpublished Manuscript, Bank of Italy.

[17] Cunha, Flavio, and James J. Heckman. 2008. Formulating, Identifying and Estimating the Technology of Cognitive and Noncognitive Skill Formation. The Journal of Human Resources 43(4): $738-82$.

[18] Cunha, Flavio, James J. Heckman, and Susanne M. Schennach. 2010. Estimating the Technology of Cognitive and Noncognitive Skill Formation. Econometrica 78(3): 883-931.

[19] Cunha, Flavio, Irma Elo, and Jennifer Culhane. 2013. Eliciting maternal expectations about the technology of cognitive skill formation. National Bureau of Economic Research Working Paper 19144.

[20] Cunha, Flavio, James J. Heckman, Lance Lochner, and Dimitriy V. Masterov. 2006. Interpreting the evidence on life cycle skill formation. In E.A. Hanushek and F. Welch, Handbook of the Economics of Education pp. 697-812. Amsterdam: North-Holland.

[21] Cunningham, Hugh. 1995. Children 8 Childhood in Western Society Since 1500. London: Longman.

[22] Danziger, Sheldon and Rouse, Cecilia Elena. 2008. The Price of Independence: The Economics of Early Adulthood. New York: Russell Sage Foundation.

[23] De Mause, Lloyd. 1974. The History of Childhood. New York: A Division of Atcom.

[24] Del Boca, Daniela, Christopher Flinn, and Matthew Wiswall. 2014. Household choices and child development. The Review of Economic Studies 81(1): 137-185.

[25] Doepke, Matthias, and Fabrizio Zilibotti. 2014. Parenting with style: Altruism and paternalism in intergenerational preference transmission. National Bureau of Economic Research Working Paper 20214.

[26] Francesconi, Marco, and James J. Heckman. 2016. Symposium on Child Development and Parental Investment: Introduction. In Symposium on Child Development and Parental Investment: Introduction. IZA Discussion Paper 9977. 
[27] Furstenberg, Frank F., Sheela Kennedy, Vonnie C. McLoyd, Ruben G. Rumbaut, and Richard A. Settersten. 2004. Growing up is harder to do. Contexts 3(3): 33-41.

[28] Gallup Organization. Gallup Poll, Aug, 1995 [survey question]. USGALLUP.95ABUS.Q26. Gallup Organization [producer]. Cornell University, Ithaca, NY: Roper Center for Public Opinion Research, iPOLL [distributor], accessed Jan-9-2017.

[29] Gayle, George-Levi, Limor Golan, and Mehmet A. Soytas. 2015. What Accounts for the Racial Gap in Time Allocation and Intergenerational Transmission of Human Capital?.

[30] Gershoff, Elizabeth, Purtell, Kelly M., Holas, Igor. 2015. Corporal Punishment in U.S. Public Schools: Legal Precedents, Current Practices, and Future Policy. Springer International Publishing.

[31] Goldin, Claudia. 1994. Understanding the gender gap: An economic history of American women. Equal employment opportunity: Labor market discrimination and public policy 17-26.

[32] Griffin, Ashleigh S., Stuart A. West, and Angus Buckling. 2004. Cooperation and competition in pathogenic bacteria. Nature 430(7003): 1024-1027.

[33] Hacker, J. David. 2003. Rethinking the "Early" Decline of Marital Fertility in the United States. Demography 40(4): 605-20.

[34] Hao, Lingxin, V. Joseph Hotz, and Ginger Z. Jin. 2008. Games parents and adolescents play: Risky behaviour, parental reputation and strategic transfers. The Economic Journal 118(528): 515-555.

[35] Harper, Alan B. 1986. The Evolution of Begging: Sibling Competition and Parent-Offspring Conflict. The American Naturalist 128(1): 99-114.

[36] Heckman, James J., and Stefano Mosso. 2014. The economics of human development and social mobility. National Bureau of Economic Research Working Paper 19925.

[37] Hobbs, Frank and Nicole Stoops. 2002. Demographic Trends in the 20th Century. U.S. Census Bureau, Census 2000 Special Reports, Series CENSR-4. 
[38] Huggett, Mark, Gustavo Ventura, and Amir Yaron. 2011. Sources of Lifetime Inequality. The American Economic Review 101(7): 2923-954.

[39] Keane, Michael P., and Kenneth I. Wolpin. 1997. The Career Decisions of Young Men. Journal of Political Economy 105(3): 473-522.

[40] Kornrich, Sabino, and Frank Furstenberg. 2013. Investing in Children: Changes in Parental Spending on Children, 1972 to 2007. Demography 50(1): 1-23.

[41] Krishna, Vijay. 2010. Auction Theory. 2nd ed. Burlington, MA: Academic Press/Elsevier.

[42] Lareau, Annette. 2003. Childhoods: Class, Race, and Family Life. Berkeley: University of California Press.

[43] Lizzeri, Alessandro, and Marciano Siniscalchi. 2008. Parental Guidance and Supervised Learning. The Quarterly Journal of Economics 123(3): 1161-195.

[44] Parents Magazine. Parents Magazine Poll (Wave 2), Jan, 1987 [survey question]. USKANE.PM0187.R20. Kane, Parsons \& Associates [producer]. Cornell University, Ithaca, NY: Roper Center for Public Opinion Research, iPOLL [distributor], accessed Jan-9-2017.

[45] Plumb, J. H. 1975. The New World of Children in Eighteenth-Century England. Past $\&$ Present 67: 64-95.

[46] Pollock, Linda. 1983. Forgotten Children: Parent-Child Relations from 1500 to 1900. Cambridge: Cambridge University Press.

[47] Schoeni, Robert F., and Karen E. Ross. 2005. Material Assistance from Families during the Transition to Adulthood. University of Chicago Press.

[48] Shorter, Edward. 1977. The Making of the Modern Family. Basic Books.

[49] Smith, Tom W, Peter Marsden, Michael Hout, and Jibum Kim. General Social Surveys, 1972-2014 [machine-readable data file] /Principal Investigator, Tom W. Smith; Co-Principal Investigator, Peter V. Marsden; Co-Principal Investigator, Michael Hout; Sponsored by National Science Foundation. -NORC ed.- Chicago: NORC at the University of Chicago [producer and distributor]. 2014. 
[50] Stearns, Peter. Anxious Parents: A History of Modern Childrearing in America. New York: NYU Press, 2003. https://muse.jhu.edu/ (accessed January 11, 2017).

[51] Ruggles, Steven, Katie Genadek, Ronald Goeken, Josiah Grover, and Matthew Sobek. 2015. Integrated Public Use Microdata Series: Version 6.0 [dataset]. Minneapolis: University of Minnesota. http://doi.org/10.18128/D010.V6.0.

[52] Stone, Lawrence. 1977. The Family Sex and Marriage: In England 1500-1800. New York: Harper \& Row.

[53] Todd, Petra E., and Kenneth I. Wolpin. 2003. On the Specification and Estimation of the Production Function for Cognitive Achievement. The Economic Journal 113(485): F3-F33.

[54] Todd, Petra E., and Kenneth I. Wolpin. 2007. The Production of Cognitive Achievement in Children: Home, School, and Racial Test Score Gaps. Journal of Human Capital 1(1): 91-136.

[55] Trumbach, Randolph. 1978. The Rise of the Egalitarian Family: Aristocratic Kinship and Domestic Relations in Eighteenth-Century England. New York: Academic Press.

[56] Vogl, Tom S. 2013. Marriage Institutions and Sibling Competition: Evidence from South Asia. The Quarterly Journal of Economics 128(3): 1017-1072.

[57] Weinberg, Bruce A. 2000. An Incentive Model of the Effect of Parental Income on Children. Journal of Political Economy 109(2): 266-80.

[58] West, Stuart A., Martyn G. Murray, Carlos A. Machado, Ashleigh S. Griffin, and Edward Allen Herre. 2001. Testing Hamilton's rule with competition between relatives. Nature 409(6819): 510513.

[59] Zelizer, Viviana. 1985. Pricing the Priceless Child. New York: Basic Books. 


\section{Appendix to "When Children Rule: Parenting in Modern Families"}

This appendix presents the proofs of all the propositions and corollaries.

\section{A.1 Proof of Proposition 1}

Suppose that $N \geq 1$. Let $b\left(v_{p}^{c}\right)$ be the biding function and $\tilde{G}\left(v_{p}^{c}\right)$ the probability that child $c$ wins the auction. Then, the expected utility of child $c$ in the auction of parent $p$ is $u_{p}^{c}=$ $\int_{0}^{i^{p}} \tilde{G}\left(v_{p}^{c}\right)\left[v_{p}^{c}-b\left(v_{p}^{c}\right)\right] f\left(v_{p}^{c}\right) d v_{p}^{c}$, where $f\left(v_{p}^{c}\right)=\left(i^{p}\right)^{-1}$. The Bayesian Nash equilibrium bid function is $b\left(v_{p}^{c}\right)=\left[G\left(v_{p}^{c}\right)\right]^{-1}\left[r^{p} G\left(r^{p}\right)+\int_{r^{p}}^{v_{p}^{c}} y g(y) d y\right]$, where $G\left(v_{p}^{c}\right)=\left[F\left(v_{p}^{c}\right)\right]^{N-1}, g\left(v_{p}^{c}\right)=G^{\prime}\left(v_{p}^{c}\right)$, $F\left(v_{p}^{c}\right)=v_{p}^{c} / i^{p}$, and $r^{p}$ is the reserve price set by parent $p$ (see Krishna 2010). Therefore:

$$
\begin{aligned}
b\left(v_{p}^{c}\right) & =\left[G\left(v_{p}^{c}\right)\right]^{-1}\left[r^{p} G\left(r^{p}\right)+\int_{r^{p}}^{v_{p}^{c}} y g(y) d y\right] \\
& =\left(\frac{i^{p}}{v_{p}^{c}}\right)^{N-1}\left[r^{p}\left(\frac{r^{p}}{i^{p}}\right)^{N-1}+(N-1) \int_{r^{p}}^{v_{p}^{c}}\left(\frac{y}{i^{p}}\right)^{N-1} d y\right] \\
& =\left(\frac{i^{p}}{v_{p}^{c}}\right)^{N-1}\left\{r^{p}\left(\frac{r^{p}}{i^{p}}\right)^{N-1}+\frac{(N-1)}{N}\left(\frac{1}{i^{p}}\right)^{N-1}\left[\left(v_{p}^{c}\right)^{N}-\left(r^{p}\right)^{N}\right]\right\} \\
& =\frac{(N-1) v_{p}^{c}+\left(r^{p}\right)^{N}\left(v_{p}^{c}\right)^{1-N}}{N} .
\end{aligned}
$$

In equilibrium, the expected utility of a child in auction $p$ is $\mathbf{E}\left(u_{p}^{c}\right)=$ $\int_{r^{p}}^{i^{p}} G\left(v_{p}^{c}\right)\left[v_{p}^{c}-b\left(v_{p}^{c}\right)\right] f\left(v_{p}^{c}\right) d v_{p}^{c}$. Therefore:

$$
\begin{aligned}
\mathbf{E}\left(u_{p}^{c}\right) & =\int_{r^{p}}^{i^{p}} G\left(v_{p}^{c}\right)\left[v_{p}^{c}-b\left(v_{p}^{c}\right)\right] f\left(v_{p}^{c}\right) d v_{p}^{c} \\
& =\int_{r^{p}}^{i^{p}}\left(\frac{v_{p}^{c}}{i^{p}}\right)^{N-1}\left[v_{p}^{c}-\frac{(N-1) v_{p}^{c}+\left(r^{p}\right)^{N}\left(v_{p}^{c}\right)^{1-N}}{N}\right] \frac{1}{i^{p}} d v_{p}^{c} \\
& =\left(\frac{1}{i^{p}}\right)^{N} \int_{r^{p}}^{i^{p}} \frac{\left(v_{p}^{c}\right)^{N}-\left(r^{p}\right)^{N}}{N} d v_{p}^{c} \\
& =\frac{\left(i^{p}\right)^{N+1}-(N+1)\left(r^{p}\right)^{N} i^{p}+N\left(r^{p}\right)^{N+1}}{\left(i^{p}\right)^{N} N(N+1)} .
\end{aligned}
$$

In equilibrium, the expected behavior of children in the auction of parent $p$ 
is $\sum_{c=1}^{N} \mathbf{E}\left(b_{p}^{c}\right)=N\left\{r^{p}\left[1-F\left(r^{p}\right)\right] G\left(r^{p}\right)+\int_{r^{p}}^{i^{p}} v_{p}^{c}\left[1-F\left(v_{p}^{c}\right)\right] g\left(v_{p}^{c}\right) d v_{p}^{c}\right\} \quad$ or, equivalently, $\sum_{c=1}^{N} \mathbf{E}\left(b_{p}^{c}\right)=N \int_{r^{p}}^{i^{p}} b\left(v_{p}^{c}\right)\left[F\left(v_{p}^{c}\right)\right]^{N-1} f\left(v_{p}^{c}\right) d v_{p}^{c}$. Therefore:

$$
\begin{aligned}
\sum_{c=1}^{N} \mathbf{E}\left(b_{p}^{c}\right) & =N \int_{r^{p}}^{i^{p}} b\left(v_{p}^{c}\right)\left[F\left(v_{p}^{c}\right)\right]^{N-1} f\left(v_{p}^{c}\right) d v_{p}^{c} \\
& =N \int_{r^{p}}^{i^{p}}\left[\frac{(N-1) v_{p}^{c}+\left(r^{p}\right)^{N}\left(v_{p}^{c}\right)^{1-N}}{N}\right]\left(\frac{v_{p}^{c}}{i^{p}}\right)^{N-1} \frac{1}{i^{p}} d v_{p}^{c} \\
& =\frac{N}{\left(i^{p}\right)^{N}} \int_{r^{p}}^{i^{p}}\left[\frac{(N-1)\left(v_{p}^{c}\right)^{N}+\left(r^{p}\right)^{N}}{N}\right] d v_{p}^{c} \\
& =\frac{N}{\left(i^{p}\right)^{N}}\left[\frac{(N-1)\left(i^{p}\right)^{N+1}}{N(N+1)}+\frac{\left(r^{p}\right)^{N} i^{p}}{N}-\frac{2\left(r^{p}\right)^{N+1}}{(N+1)}\right] .
\end{aligned}
$$

Finally, in order to maximize $\sum_{c=1}^{N} \mathbf{E}\left(b_{p}^{c}\right)$, parent $p$ must select $r^{p}=\left(1-F\left(r^{p}\right)\right) / f\left(r^{p}\right)$, i.e., $r^{p}=$ $i^{p} / 2$. Introducing this into $u_{p}^{c}$ and $\sum_{c=1}^{N} \mathbf{E}\left(b_{p}^{c}\right)$ we obtain $\sum_{c=1}^{N} \mathbf{E}\left(b_{p}^{c}\right)=f(N) i^{p}$ and $\mathbf{E}\left(u_{p}^{c}\right)=g(N) i^{p}$, where $f(N)=\frac{(N-1)(2)^{N+1}+2}{(N+1)(2)^{N+1}}$ and $g(N)=\frac{2^{N+1}-(N+2)}{2^{N+1} N(N+1)}$.

\section{A.2 Proof of Proposition 2}

Employing Proposition 1, parent $p$ expected utility can be rewritten as follows:

$$
u^{p}=\left[\frac{y^{p}-i^{p}+\beta_{x}\left(y^{-p}-i^{-p}\right)}{1+\beta_{x}}\right]^{\alpha_{x}}\left[\frac{f(N)\left(i^{p}+\beta_{b} i^{-p}\right)}{1+\beta_{b}}\right]^{\alpha_{b}}
$$

which is a twice continuously differentiable function for $\left(i^{m}, i^{f}\right) \in\left[0, y^{m}\right] \times\left[0, y^{f}\right]$.Then:

$$
\begin{aligned}
\frac{\partial u^{p}}{\partial i^{p}} & =u^{p}\left[\frac{-\alpha_{x}}{y^{p}-i^{p}+\beta_{x}\left(y^{-p}-i^{-p}\right)}+\frac{\alpha_{b}}{i^{p}+\beta_{b} i^{-p}}\right], \\
\frac{\partial^{2} u^{p}}{\left(\partial i^{p}\right)^{2}} & =-u^{p}\left\{\begin{array}{c}
2 \frac{\alpha_{x}}{y^{p}-i^{p}+\beta_{x}\left(y^{-p}-i^{-p}\right)} \frac{\alpha_{b}}{i^{p}+\beta_{b} i^{-p}} \\
\frac{\alpha_{x} \alpha_{b}}{\left[y^{p}-i^{p}+\beta_{x}\left(y^{-p}-i^{-p}\right)\right]^{2}}+\frac{\alpha_{b} \alpha_{x}}{\left(i^{p}+\beta_{b} i^{-p}\right)^{2}}
\end{array}\right\} .
\end{aligned}
$$

Note that $\partial^{2} u^{p} /\left(\partial i^{p}\right)^{2}<0$, which implies that $u^{p}$ is strictly concave in $i^{p}$. Therefore, from Glicksberg' theorem, there exists a pure strategy Nash equilibrium. Moreover, the reaction function of parent $p$ is given by: 


$$
i^{p}\left(i^{-p}\right)= \begin{cases}0 & \text { if } i^{-p} \geq \frac{\alpha_{b}\left(y^{p}+\beta_{x} y^{-p}\right)}{\left(\alpha_{b} \beta_{x}+\alpha_{x} \beta_{b}\right)}, \\ \alpha_{b}\left(y^{p}+\beta_{x} y^{-p}\right)-\left(\alpha_{b} \beta_{x}+\alpha_{x} \beta_{b}\right) i^{-p} & \text { if } \frac{\alpha_{b} \beta_{x} y^{-p}-\alpha_{x} y^{p}}{\left(\alpha_{b} \beta_{x}+\alpha_{x} \beta_{b}\right)}<i^{-p}<\frac{\alpha_{b}\left(y^{p}+\beta_{x} y^{-p}\right)}{\left(\alpha_{b} \beta_{x}+\alpha_{x} \beta_{b}\right)}, \\ y^{p} & \text { if } i^{-p} \leq \frac{\alpha_{b} \beta_{x} y^{-p}-\alpha_{x} y^{p}}{\left(\alpha_{b} \beta_{x}+\alpha_{x} \beta_{b}\right)} .\end{cases}
$$

Before proceeding, we prove that under the assumption that $\beta_{x}<\alpha_{x}<\frac{\alpha_{b}}{\beta_{b}}$, the father always plays an interior solution. $i^{f}\left(i^{m}\right) \in\left(0, y^{f}\right)$ if and only if $\frac{\alpha_{b} \beta_{x} y^{m}-\alpha_{x} y^{f}}{\left(\alpha_{b} \beta_{x}+\alpha_{x} \beta_{b}\right)}<i^{m}<\frac{\alpha_{b}\left(y^{f}+\beta_{x} y^{m}\right)}{\left(\alpha_{b} \beta_{x}+\alpha_{x} \beta_{b}\right)}$. The first inequality always holds because $\beta_{x}<\alpha_{x}$ and $y^{f} \geq y^{m}$ implies $\alpha_{b} \beta_{x} y^{m}<\alpha_{x} y^{f}$. The second inequality always holds because $\alpha_{x} \beta_{b}<\alpha_{b}$ and $y^{f} \geq y^{m}$ implies $y^{m} \alpha_{x} \beta_{b}<\alpha_{b} y^{f}$, which implies $y^{m}<\frac{\alpha_{b}\left(y^{f}+\beta_{x} y^{m}\right)}{\left(\alpha_{b} \beta_{x}+\alpha_{x} \beta_{b}\right)}$. Since the father always plays an interior solution we must consider three possible situations.

(i) Suppose that $i^{m}=0$. Then, $i^{f}=\alpha_{b}\left(y^{f}+\beta_{x} y^{m}\right)$. For this to be a Nash equilibrium, it must be the case that $i^{f} \geq \frac{\alpha_{b}\left(y^{m}+\beta_{x} y^{f}\right)}{\left(\alpha_{b} \beta_{x}+\alpha_{x} \beta_{b}\right)}$, i.e., whenever $\alpha_{x}\left(\beta_{b}-\beta_{x}\right) y^{f} \geq\left[\alpha_{x}\left(1-\beta_{b} \beta_{x}\right)+\alpha_{b}\left(1-\beta_{x} \beta_{x}\right)\right] y^{m}$. There is only one way in which this inequality can be satisfied, namely when $\beta_{b}>\beta_{x}$ and $\frac{y^{m}}{y^{f}} \leq \bar{y}^{r}=$ $\frac{\alpha_{x}\left(\beta_{b}-\beta_{x}\right)}{\alpha_{x}\left(1-\beta_{b} \beta_{x}\right)+\alpha_{b}\left(1-\beta_{x} \beta_{x}\right)}$.

(ii) Suppose that $i^{m}=y^{m}$. Then, $i^{f}=\alpha_{b} y^{f}-\alpha_{x} \beta_{b} y^{m}$. For this to be a Nash equilibrium, $i^{f} \leq$ $\frac{\alpha_{b} \beta_{x} y^{f}-\alpha_{x} y^{m}}{\left(\alpha_{b} \beta_{x}+\alpha_{x} \beta_{b}\right)}$, i.e., whenever $\left[1-\left(\alpha_{b} \beta_{x}+\alpha_{x} \beta_{b}\right) \beta_{b}\right] \alpha_{x} y^{m} \leq \alpha_{x}\left(\beta_{x}-\beta_{b}\right) \alpha_{b} y^{f}$. There is only one way in which this inequality, namely, $\beta_{x}>\beta_{b}$ and $\frac{y^{m}}{y^{f}} \leq \hat{y}^{r}=\frac{\left(\beta_{x}-\beta_{b}\right) \alpha_{b}}{1-\left(\alpha_{b} \beta_{x}+\alpha_{x} \beta_{b}\right) \beta_{b}}$.

(iii) Suppose that $i^{m} \in\left(0, y^{m}\right)$. Then:

$$
\begin{gathered}
i^{m}=i^{m, *}=\alpha_{b}\left[\left(\delta_{1}-\beta_{x} \delta_{2}\right) y^{m}+\left(\beta_{x} \delta_{1}-\delta_{2}\right) y^{f}\right], \\
i^{f}=i^{f, *}=\alpha_{b}\left[\left(\delta_{1}-\beta_{x} \delta_{2}\right) y^{f}+\left(\beta_{x} \delta_{1}-\delta_{2}\right) y^{m}\right],
\end{gathered}
$$

where $\delta_{1}=\frac{\left(\alpha_{x}+\alpha_{b}\right)}{1-\left(\alpha_{b} \beta_{x}+\alpha_{x} \beta_{b}\right)^{2}}$ and $\delta_{2}=\frac{\alpha_{b} \beta_{x}+\alpha_{x} \beta_{b}}{1-\left(\alpha_{b} \beta_{x}+\alpha_{x} \beta_{b}\right)^{2}}$. For this to be a Nash equilibrium $\frac{\alpha_{b} \beta_{x} y^{f}-\alpha_{x} y^{m}}{\left(\alpha_{b} \beta_{x}+\alpha_{x} \beta_{b}\right)}<$ $i^{f}<\frac{\alpha_{b}\left(y^{m}+\beta_{x} y^{f}\right)}{\left(\alpha_{b} \beta_{x}+\alpha_{x} \beta_{b}\right)}$, i.e., whenever $\frac{\alpha_{b} \beta_{x} y^{f}-\alpha_{x} y^{m}}{\left(\alpha_{b} \beta_{x}+\alpha_{x} \beta_{b}\right)}<\alpha_{b}\left[\left(\delta_{1}-\delta_{2} \beta_{x}\right) y^{f}+\left(\delta_{1} \beta_{x}-\delta_{2}\right) y^{m}\right]<\frac{\alpha_{b}\left(y^{m}+\beta_{x} y^{f}\right)}{\left(\alpha_{b} \beta_{x}+\alpha_{x} \beta_{b}\right)}$.

These inequality can be rewritten as follows

$$
\begin{gathered}
{\left[\left(\alpha_{b} \beta_{x}+\alpha_{x} \beta_{b}\right)\left(\delta_{1} \beta_{x}-\delta_{2}\right)-1\right] y^{m}<\left[\beta_{x}-\left(\alpha_{b} \beta_{x}+\alpha_{x} \beta_{b}\right)\left(\delta_{1}-\delta_{2} \beta_{x}\right)\right] y^{f}} \\
\alpha_{b}\left[\beta_{x}-\left(\alpha_{b} \beta_{x}+\alpha_{x} \beta_{b}\right)\left(\delta_{1}-\delta_{2} \beta_{x}\right)\right] y^{f}<\left[\alpha_{x}+\alpha_{b}\left(\alpha_{b} \beta_{x}+\alpha_{x} \beta_{b}\right)\left(\delta_{1} \beta_{x}-\delta_{2}\right)\right] y^{m}
\end{gathered}
$$

Suppose that $\beta_{b}>\beta_{x}$. Then, $\left(\alpha_{b} \beta_{x}+\alpha_{x} \beta_{b}\right)\left(\delta_{1} \beta_{x}-\delta_{2}\right)<1$ and $\beta_{x}<\left(\alpha_{b} \beta_{x}+\alpha_{x} \beta_{b}\right)\left(\delta_{1}-\delta_{2} \beta_{x}\right)$. Then, the second inequality always holds, while the first holds if and only if:

$$
\frac{y^{m}}{y^{f}}>\frac{\left(\alpha_{b} \beta_{x}+\alpha_{x} \beta_{b}\right)\left(\delta_{1}-\delta_{2} \beta_{x}\right)-\beta_{x}}{1-\left(\alpha_{b} \beta_{x}+\alpha_{x} \beta_{b}\right)\left(\delta_{1} \beta_{x}-\delta_{2}\right)}=\bar{y}^{r}
$$


Suppose that $\beta_{b}<\beta_{x}$. Then, $\left(\alpha_{b} \beta_{x}+\alpha_{x} \beta_{b}\right)\left(\delta_{1} \beta_{x}-\delta_{2}\right)-1<\beta_{x}-\left(\alpha_{b} \beta_{x}+\alpha_{x} \beta_{b}\right)\left(\delta_{1}-\delta_{2} \beta_{x}\right)$ and $\beta_{x}>$ $\left(\alpha_{b} \beta_{x}+\alpha_{x} \beta_{b}\right)\left(\delta_{1}-\delta_{2} \beta_{x}\right)$. Then, the first inequality always holds (recall that $\left.y^{f} \geq y^{m}\right)$, while the second inequality holds if and only if:

$$
\frac{y^{m}}{y^{f}}>\frac{\alpha_{b}\left[\beta_{x}-\left(\alpha_{b} \beta_{x}+\alpha_{x} \beta_{b}\right)\left(\delta_{1}-\delta_{2} \beta_{x}\right)\right]}{\alpha_{x}+\alpha_{b}\left(\alpha_{b} \beta_{x}+\alpha_{x} \beta_{b}\right)\left(\delta_{1} \beta_{x}-\delta_{2}\right)}=\hat{y}^{r} .
$$

Summing up, we have the following two possible cases.

Case 1: $\beta_{b}>\beta_{x}$. Then, $\left(i^{m}, i^{f}\right)=\left(0, \alpha_{b}\left(y^{f}+\beta_{x} y^{m}\right)\right)$ is the unique Nash equilibrium for $y^{m} / y^{f} \leq \bar{y}^{r}$, while $\left(i^{m}, i^{f}\right)=\left(i^{m, *}, i^{f \cdot *}\right)$ is the unique Nash equilibrium when $y^{m} / y^{f}>\bar{y}^{r}$.

Case 2: $\beta_{b}<\beta_{x} .\left(i^{m}, i^{f}\right)=\left(y^{m}, \alpha_{b} y^{f}-\alpha_{x} \beta_{b} y^{m}\right)$ is the unique Nash equilibrium when $y^{m} / y^{f} \leq \hat{y}^{r}$ and $\left(i^{m}, i^{f}\right)=\left(i^{m, *}, i^{f \cdot *}\right)$ is the unique Nash equilibrium when $y^{m} / y^{f}>\hat{y}^{r}$.

\section{A.3 Proof of Corollary 1}

Case 1: $\beta_{b}>\beta_{x}$. From Proposition 1, in equilibrium, $i^{m}+i^{f}=\alpha_{b}\left(y^{f}+\beta_{x} y^{m}\right)$ when $y^{m} / y^{f} \leq \bar{y}^{r}$, while $i^{m}+i^{f}=i^{m *}+i^{f, *}=\alpha_{b}\left(1+\beta_{x}\right)\left(\delta_{1}-\delta_{2}\right)\left(y^{m}+y^{f}\right)$ when $y^{m} / y^{f}>\bar{y}^{r}$. Thus:

$$
\frac{i^{m}+i^{f}}{y^{m}+y^{f}}= \begin{cases}\alpha_{b}\left(1+\beta_{x}\right)\left(\delta_{1}-\delta_{2}\right) & \text { if } y^{m} / y^{f}>\bar{y}^{r}, \\ \frac{\alpha_{b}\left(y^{f}+\beta_{x} y^{m}\right)}{\left(y^{m}+y^{f}\right)} & \text { if } y^{m} / y^{f} \leq \bar{y}^{r} .\end{cases}
$$

Moreover, for $y^{m} / y^{f} \leq \bar{y}^{r}$, the derivative of $\frac{i^{m}+i^{f}}{y^{m}+y^{f}}$ with respect to $y^{m} / y^{f}$ is given by:

$$
\frac{d\left[\left(i^{m}+i^{f}\right) /\left(y^{m}+y^{f}\right)\right]}{d\left(y^{m} / y^{f}\right)}=\frac{-\left(1-\beta_{x}\right)}{\left(1+y^{m} / y^{f}\right)^{2}}<0 .
$$

Also note that $\alpha_{b}\left(1+\beta_{x}\right)\left(\delta_{1}-\delta_{2}\right)=\frac{\alpha_{b}\left(1+\beta_{x} \bar{y}^{r}\right)}{\left(1+\bar{y}^{r}\right)}$. Thus, $\left(i^{m}+i^{f}\right) /\left(y^{m}+y^{f}\right)$ is weakly decreasing in $y^{m} / y^{f}$.

Case 2: $\beta_{b}<\beta_{x}$. From Proposition 1, in equilibrium, $i^{m}+i^{f}=\alpha_{b} y^{f}+\left[\alpha_{x}\left(1-\beta_{b}\right)+\alpha_{b}\right] y^{m}$ when $y^{m} / y^{f} \leq \hat{y}^{r}$, while $i^{m}+i^{f}=i^{m *}+i^{f, *}$ when $y^{m} / y^{f}>\bar{y}^{r}$. Thus:

$$
\frac{i^{m}+i^{f}}{y^{m}+y^{f}}= \begin{cases}\alpha_{b}\left(1+\beta_{x}\right)\left(\delta_{1}-\delta_{2}\right) & \text { if } y^{m} / y^{f}>\hat{y}^{r}, \\ \frac{\alpha_{b} y^{f}+\left[\alpha_{x}\left(1-\beta_{b}\right)+\alpha_{b}\right] y^{m}}{\left(y^{m}+y^{f}\right)} & \text { if } y^{m} / y^{f} \leq \hat{y}^{r} .\end{cases}
$$

Moreover, for $y^{m} / y^{f} \leq \hat{y}^{r}$, the derivative of $\frac{i^{m}+i^{f}}{y^{m}+y^{f}}$ with respect to $y^{m} / y^{f}$ is given by:

$$
\frac{d\left[\left(i^{m}+i^{f}\right) /\left(y^{m}+y^{f}\right)\right]}{d\left(y^{m} / y^{f}\right)}=\frac{\alpha_{x}\left(1-\beta_{b}\right)}{\left(y^{m} / y^{f}+1\right)^{2}}>0 .
$$


Also note that $\alpha_{b}\left(1+\beta_{x}\right)\left(\delta_{1}-\delta_{2}\right)=\frac{\alpha_{b}+\left[\alpha_{x}\left(1-\beta_{b}\right)+\alpha_{b}\right] \hat{y}^{r}}{\left(1+\hat{y}^{r}\right)}$. Thus, $\left(i^{m}+i^{f}\right) /\left(y^{m}+y^{f}\right)$ is weakly increasing in $y^{m} / y^{f}$.

\section{A.4 Proof of Corollary 2}

Under the assumptions in Proposition 2, when $\beta_{b}<\beta_{x}$ and $y^{m} / y^{f} \leq \hat{y}^{r}$, in equilibrium, $N u^{c}, u^{f}$ and $u^{m}$ are given by:

$$
\begin{aligned}
N u^{c} & =N g(N)\left[\frac{\alpha_{b}+\left(1-\alpha_{x} \beta_{b}\right) y^{m} / y^{f}}{1+y^{m} / y^{f}}\right]\left(y^{f}+y^{m}\right), \\
u^{f} & =\left(\frac{\alpha_{x}}{1+\beta_{x}}\right)^{\alpha_{x}}\left(\frac{f(N) \alpha_{b}}{1+\beta_{b}}\right)^{\alpha_{b}}\left(\frac{1+\beta_{b} y^{m} / y^{f}}{1+y^{m} / y^{f}}\right)\left(y^{f}+y^{m}\right), \\
u^{m} & =\left(\frac{\alpha_{x} \beta_{x}}{1+\beta_{x}}\right)^{\alpha_{x}}\left(\frac{f(N)}{1+\beta_{b}}\right)^{\alpha_{b}}\left(\frac{1+\beta_{b} y^{m} / y^{f}}{1+y^{m} / y^{f}}\right)^{\alpha_{x}}\left[\frac{\beta_{b} \alpha_{b}+\left(1-\alpha_{x}\left(\beta_{b}\right)^{2}\right) y^{m} / y^{f}}{1+y^{m} / y^{f}}\right]^{\alpha_{b}}\left(y^{f}+y^{m}\right),
\end{aligned}
$$

respectively. Therefore, in equilibrium, the ratio between the payoff of the children and the father is given by:

$$
\frac{N u^{c}}{u^{f}}=\frac{N g(N)\left[\alpha_{b}+\left(1-\alpha_{x} \beta_{b}\right) y^{m} / y^{f}\right]}{\left(\frac{\alpha_{x}}{1+\beta_{x}}\right)^{\alpha_{x}}\left(\frac{f(N) \alpha_{b}}{1+\beta_{b}}\right)^{\alpha_{b}}\left(1+\beta_{b} y^{m} / y^{f}\right)} .
$$

From a direct inspection of this expression, it is easy to verify that $N u^{c} / u^{f}$ is independent of $\left(y^{m}+y^{f}\right)$. The derivative of $N u^{c} / u^{f}$ with respect to $y^{m} / y^{f}$ is positive. Thus, $N u^{c} / u^{f}$ is increasing in $y^{m} / y^{f}$. The derivative of $N u^{c} / u^{f}$ with respect to $N$ is negative if and only if

$$
\left[\frac{(2)^{N+1} \ln 2-1}{(2)^{N+1}-(N+2)}\right]<\alpha_{b}\left[\frac{(2)^{N+1}+(N-1)(2)^{N+1} \ln (2)}{(N-1)(2)^{N+1}+2}\right]+\left(1-\alpha_{b}\right)\left[\frac{1+(N+1) \ln 2}{N+1}\right]
$$

For $N \geq 1$, the left hand side of this inequality is always strictly lower than the first squared bracket on the right hand side. The left hand side is also strictly lower than the second squared bracket on the right hand side for $1 \leq N<\hat{N} \in(2,3)$, where $(2)^{\hat{N}+1}=1+(\hat{N}+2)(\hat{N}+1) \ln (2)$, while the opposite holds when $N>\hat{N}$. Therefore, for $N \geq \hat{N}, \partial\left(N u^{c} / u^{f}\right) / \partial N<0$ and, hence, $N u^{c} / u^{f}$ is decreasing in $N$. For $N<\hat{N}$, the left hand side is strictly greater than the second squared bracket on the right hand side. Since the right hand side is just a weighted average of $\left[\frac{(2)^{N+1}+(N-1)(2)^{N+1} \ln (2)}{(N-1)(2)^{N+1}+2}\right]$ and $\left[\frac{1+(N+1) \ln 2}{N+1}\right]$, a simple application of the intermediate value theorem implies that for each $N<\hat{N}$ there must exist $\bar{\alpha}_{b}(N) \in(0,1)$ such that for all $\alpha_{b} \geq \bar{\alpha}_{b}(N)$ the inequality holds. Define $\bar{\alpha}_{b}=\max _{N \in[1, \hat{N}]} \bar{\alpha}_{b}(N)$. Then, when $\alpha_{b} \geq \bar{\alpha}_{b}, \partial\left(N u^{c} / u^{f}\right) / \partial N<0$ for all $N \geq 1$ and, hence, $N u^{c} / u^{f}$ is decreasing for all $N \geq 1$. 
In equilibrium, the ratio between the payoff of the children and the mother is given by:

$$
\frac{N u^{c}}{u^{m}}=\frac{N g(N)\left[\alpha_{b}+\left(1-\alpha_{x} \beta_{b}\right)\left(y^{m} / y^{f}\right)\right]}{\left(\frac{\alpha_{x} \beta_{x}}{1+\beta_{x}}\right)^{\alpha_{x}}\left(\frac{f(N)}{1+\beta_{b}}\right)^{\alpha_{b}}\left[1+\beta_{b}\left(y^{m} / y^{f}\right)\right]^{\alpha_{x}}\left\{\beta_{b} \alpha_{b}+\left[1-\left(\beta_{b}\right)^{2} \alpha_{x}\right]\left(y^{m} / y^{f}\right)\right\}^{\alpha_{b}}}
$$

From a direct inspection of this expression, it is easy to verify that $N u^{c} / u^{m}$ is independent of $\left(y^{m}+y^{f}\right)$. The derivative of $N u^{c} / u^{m}$ with respect to $y^{m} / y^{f}$ is positive (negative) if and only if $y^{m} / y^{f}>\tilde{y}^{r}\left(y^{m} / y^{f}<\right.$ $\left.\tilde{y}^{r}\right)$, where:

$$
\tilde{y}^{r}=\frac{\left(1-\beta_{b}\right)^{2}\left(1-\alpha_{x}\right)+\left(\alpha_{x}\right)^{2}\left(1+\beta_{b}\right)}{\alpha_{x}-\beta_{b}+\alpha_{x} \beta_{b}-\left(\alpha_{x}\right)^{2} \beta_{b}\left(1-\beta_{b}\right)\left(1+\beta_{b}\right)}-1 .
$$

Thus, $N u^{c} / u^{f}$ decreasing in $y^{m} / y^{f}$ for $y^{m} / y^{f} \leq \tilde{y}^{r}$ and increasing for $\tilde{y}^{r} \leq y^{m} / y^{f} \leq \hat{y}^{r}$. Finally, note that the sign of the derivative of $N u^{c} / u^{m}$ with respect to $N$ is the same as the sign of the derivative of $N u^{c} / u^{f}$ with respect to $N$. Hence, the same proof that employed to sign $\partial\left(N u^{c} / u^{f}\right) / \partial N$ applies to $\partial\left(N u^{c} / u^{m}\right) / \partial N$.

In equilibrium, the ratio between the payoff of the mother and the father is given by:

$$
\frac{u^{m}}{u^{f}}=\left(\frac{\beta_{x}}{\alpha_{x}}\right)^{\alpha_{x}}\left\{\frac{\beta_{b} \alpha_{b}+\left[1-\alpha_{x}\left(\beta_{b}\right)^{2}\right] y^{m} / y^{f}}{\alpha_{b}+\alpha_{b} \beta_{b} y^{m} / y^{f}}\right\}^{\alpha_{b}},
$$

From a direct inspection of this expression, it is easy to verify that $u^{m} / u^{f}$ does not depend on $\left(y^{m}+y^{f}\right)$ or $N$. The derivative of $u^{m} / u^{f}$ with respect to $y^{m} / y^{f}$ is positive. Thus, $u^{m} / u^{f}$ is increasing in $y^{m} / y^{f}$.

\section{A.5 Proof of Proposition 3}

Suppose that the father has selected the punishment level $z^{f} \in\left[0, \bar{z}^{f}\right]$. Then, employing the same steps we use in the proof of Proposition 2, the reaction function of parent $p$ is given by:

$$
i^{p}\left(i^{-p}\right)=\left\{\begin{array}{lc}
0 & \text { if } i^{-p} \geq \frac{\alpha_{b}\left(y^{p}+\beta_{x} y^{-p}\right)}{\left(\alpha_{b} \beta_{x}+\alpha_{x} \beta_{b}\right)}-\frac{\alpha_{x}(N)^{\gamma}\left(z^{p}\right)^{1-\gamma}}{\left(\alpha_{b} \beta_{x}+\alpha_{x} \beta_{b}\right) f(N),}, \\
\alpha_{b}\left(y^{p}+\beta_{x} y^{-p}\right)-\left(\alpha_{b} \beta_{x}+\alpha_{x} \beta_{b}\right) i^{-p} & \frac{\alpha_{b} \beta_{x} y^{-p}-\alpha_{x} y^{p}}{\left(\alpha_{b} \beta_{x}+\alpha_{x} \beta_{b}\right)}-\frac{\alpha_{x}(N)^{\gamma}\left(z^{p}\right)^{1-\gamma}}{f(N)\left(\alpha_{b} \beta_{x}+\alpha_{x} \beta_{b}\right)}<i^{-p} \\
-\frac{\alpha_{x}\left(z^{p}+\beta_{b} z^{-p}\right)}{f(N)} & \text { if } \& i^{-p}<\frac{\alpha_{b}\left(y^{p}+\beta_{x} y^{-p}\right)}{\left(\alpha_{b} \beta_{x}+\alpha_{x} \beta_{b}\right)}-\frac{\alpha_{x}(N)^{\gamma}\left(z^{p}\right)^{1-\gamma}}{\left(\alpha_{b} \beta_{x}+\alpha_{x} \beta_{b}\right) f(N)} \\
y^{p} & \text { if } i^{-p} \leq \frac{\alpha_{b} \beta_{x} y^{-p}-\alpha_{x} y^{p}}{\left(\alpha_{b} \beta_{x}+\alpha_{x} \beta_{b}\right)}-\frac{\alpha_{x}(N)^{\gamma}\left(z^{p}\right)^{1-\gamma}}{f(N)\left(\alpha_{b} \beta_{x}+\alpha_{x} \beta_{b}\right)} .
\end{array},\right.
$$

Note that $i^{f}\left(i^{m}\right) \in\left(0, y^{f}\right)$ if and only if $\frac{\alpha_{b} \beta_{x} y^{m}-\alpha_{x} y^{f}}{\left(\alpha_{b} \beta_{x}+\alpha_{x} \beta_{b}\right)}-\frac{\alpha_{x}(N)^{\gamma}\left(z^{p}\right)^{1-\gamma}}{f(N)\left(\alpha_{b} \beta_{x}+\alpha_{x} \beta_{b}\right)}<i^{m}<\frac{\alpha_{b}\left(y^{f}+\beta_{x} y^{m}\right)}{\left(\alpha_{b} \beta_{x}+\alpha_{x} \beta_{b}\right)}-$ $\frac{\alpha_{x}(N)^{\gamma}\left(z^{p}\right)^{1-\gamma}}{\left(\alpha_{b} \beta_{x}+\alpha_{x} \beta_{b}\right) f(N)}$. The first inequality always holds because $\beta_{x}<\alpha_{x}$ and $y^{f} \geq y^{m}$ implies $\alpha_{b} \beta_{x} y^{m}<\alpha_{x} y^{f}$. 
The second inequality holds whenever $z^{f}<\bar{z}^{f}=\left[\frac{\alpha_{b} f(N)}{\alpha_{x}(N)^{\gamma}}\right]^{\frac{1}{1-\gamma}}\left(y^{f}-\frac{\alpha_{x} \beta_{b}}{\alpha_{b}} y^{m}\right)^{\frac{1}{1-\gamma}}$. Moreover, note that $\alpha_{x} \beta_{b}<\alpha_{b}$ and $y^{f} \geq y^{m}$ implies $\bar{z}^{f}>0$. Thus, if $\beta_{x}<\alpha_{x}<\alpha_{b} / \beta_{b}, y^{f} \geq y^{m}$, and $z^{f}<\bar{z}^{f}$, the father always plays an interior solution.

Suppose that $i^{m}=y^{m}$. Then, $i^{f}=i^{f}\left(y^{m}\right)=\alpha_{b} y^{f}-\alpha_{x} \beta_{b} y^{m}-\alpha_{x}[f(N)]^{-1}(N)^{\gamma}\left(z^{f}\right)^{1-\gamma}$. For this to be a Nash equilibrium of the investment subgame it must be the case that $i^{f} \leq \frac{\alpha_{b} \beta_{x} y^{f}-\alpha_{x} y^{m}}{\left(\alpha_{b} \beta_{x}+\alpha_{x} \beta_{b}\right)}-$ $\frac{\alpha_{x} \beta_{b} z^{f}}{f(N)\left(\alpha_{b} \beta_{x}+\alpha_{x} \beta_{b}\right)}$, i.e., $\frac{y^{m}}{y^{f}} \leq \frac{1}{\hat{y}^{r}}+\frac{\alpha_{b}\left(\beta_{x}-\beta_{b}\right)(N)^{\gamma}\left(z^{f}\right)^{1-\gamma}}{\left[1-\left(\alpha_{b} \beta_{x}+\alpha_{x} \beta_{b}\right) \beta_{b}\right] f(N) y^{f}}$. Since $\beta_{x}>\beta_{b}$ and $\frac{y^{m}}{y^{f}} \leq \hat{y}^{r}$, the last inequality holds for all $z^{f}$.

Thus, when $\beta_{x}>\beta_{b}$ and $\frac{y^{m}}{y^{f}} \leq \hat{y}^{r}$, the payoff of the father as a function of $z^{f}$ is given by:

$$
\ln u^{f}=\alpha_{x} \ln \left(\frac{y^{f}-i^{f}}{1+\beta_{x}}\right)+\alpha_{b} \ln \left[\frac{f(N) i^{f}+\beta_{b} f(N) y^{m}+(N)^{\gamma}\left(z^{f}\right)^{1-\gamma}}{1+\beta_{b}}\right]-c_{z}^{f} z^{f},
$$

where $i^{f}=\alpha_{b} y^{f}-\alpha_{x} \beta_{b} y^{m}-\alpha_{x}[f(N)]^{-1}(N)^{\gamma}\left(z^{f}\right)^{1-\gamma}$. Then, $\frac{\partial \ln u^{f}}{\partial z^{f}}=\frac{(1-\gamma)(N)^{\gamma}}{f(N)\left(y^{f}+\beta_{b} y^{m}\right)\left(z^{f}\right)^{\gamma}+(N)^{\gamma} z^{f}}-c_{z}^{f}$ and $\frac{\partial^{2} \ln u^{f}}{\left(\partial z^{f}\right)^{2}}<0$. Since $\lim _{z^{f} \rightarrow 0} \frac{\partial \ln u^{f}}{\partial z^{f}}>0$, the best alternative for the father is to choose

$$
z^{f}=\left\{\begin{array}{cl}
\bar{z}^{f} & \text { if } \frac{\left(\alpha_{x}+\alpha_{b}\right)(1-\gamma)(N)^{\gamma}}{f(N)\left(y^{f}+\beta_{b} y^{m}\right)\left(\bar{z}^{f}\right)^{\gamma}+(N)^{\gamma}\left(\bar{z}^{f}\right)} \geq c_{z}^{f} \\
z^{f, *} & \text { if } \frac{\left(\alpha_{x}+\alpha_{b}\right)(1-\gamma)(N)^{\gamma}}{f(N)\left(y^{f}+\beta_{b} y^{m}\right)\left(\bar{z}^{f}\right)^{\gamma}+(N)^{\gamma}\left(\bar{z}^{f}\right)} \leq c_{z}^{f}
\end{array}\right.
$$

where $z^{f, *}$ is the unique solution to $\frac{(1-\gamma)(N)^{\gamma}}{f(N)\left(y^{f}+\beta_{b} y^{m}\right)\left(z^{f, *}\right)^{\gamma}+(N)^{\gamma}\left(z^{f, *}\right)}=c_{z}^{f}$.

\section{A.6 Proof of Corollary 3}

Under the assumption in Proposition 3, when $\frac{(1-\gamma)(N)^{\gamma}}{f(N)\left(y^{f}+\beta_{b} y^{m}\right)\left(\bar{z}^{f}\right)^{\gamma}+(N)^{\gamma}\left(\bar{z}^{f}\right)} \leq c_{z}^{f}$, the equilibrium level of punishment is given by the unique solution to $\frac{(1-\gamma)(N)^{\gamma}}{f(N)\left(y^{f}+\beta_{b} y^{m}\right)\left(z^{f, *}\right)^{\gamma}+(N)^{\gamma}\left(z^{f, *}\right)}=c_{z}^{f}$. Let $\eta_{a, b}$ denote the elasticity of $a$ with respect to $a$. A direct application of the implicit function theorem implies:

$$
\begin{aligned}
\eta_{z^{f, *}, y} & =\frac{-f(N)\left(y^{f}+\beta_{b} y^{m}\right)}{\gamma f(N)\left(y^{f}+\beta_{b} y^{m}\right)+(N)^{\gamma}\left(z^{f, *}\right)^{1-\gamma}}<0, \\
\eta_{z^{f, *}, y^{m} / y^{f}} & =\frac{\left(1-\beta_{b}\right) f(N)\left(y^{f}+y^{m}\right)}{f(N)\left(y^{f}+\beta_{b} y^{m}\right) \gamma+(N)^{\gamma}\left(z^{f, *}\right)^{1-\gamma}} \frac{\left(y^{m} / y^{f}\right)}{\left(1+y^{m} / y^{f}\right)^{2}}>0, \\
\eta_{z^{f, *}, N} & =\frac{\left(\gamma-\eta_{f, N}\right) f(N)\left(y^{f}+\beta_{b} y^{m}\right)}{\gamma f(N)\left(y^{f}+\beta_{b} y^{m}\right)\left(z^{f, *}\right)^{2(\gamma-1)}+(N)^{\gamma}\left(z^{f, *}\right)^{\gamma-1}},
\end{aligned}
$$

where $\eta_{z f, *, N}>0$ if and only if $\gamma>\eta_{f, N}$. 
Introducing $z^{f, *}$ into $i^{f}$, we obtain:

$$
\frac{i^{f}+i^{m}}{y^{f}+y^{m}}=\frac{\alpha_{b}+\left(1-\alpha_{x} \beta_{b}\right) y^{m} / y^{f}}{1+y^{m} / y^{f}}-\frac{\alpha_{x}[f(N)]^{-1}(N)^{\gamma}\left(z^{f \cdot *}\right)^{1-\gamma}}{y^{f}+y^{m}}
$$

Therefore:

$$
\frac{\partial\left(\frac{i^{f}+i^{m}}{y^{f}+y^{m}}\right)}{\partial\left(y^{m} / y^{f}\right)}=\left[\frac{f(N)\left(y^{f}+\beta_{b} y^{m}\right) \gamma+(N)^{\gamma} \gamma\left(z^{f, *}\right)^{1-\gamma}}{f(N)\left(y^{f}+\beta_{b} y^{m}\right) \gamma+(N)^{\gamma}\left(z^{f, *}\right)^{1-\gamma}}\right] \frac{\alpha_{x}\left(1-\beta_{b}\right)}{\left(1+y^{m} / y^{f}\right)^{2}}>0 .
$$

Thus, $\left(i^{f}+i^{m}\right) /\left(y^{f}+y^{m}\right)$ is increasing in $y^{m} / y^{f}$. 